Páipéar Taighde Teicniúil

Research Technical Paper

How Effective are Sovereign Bond-Backed

Securities as a Spillover Prevention Device?

David Cronin \& Peter G. Dunne 


\title{
How Effective are Sovereign Bond-Backed Securities as a Spillover Prevention Device?
}

\author{
David Cronin \\ Central Bank of Ireland
}

\author{
Peter G. Dunne \\ Central Bank of Ireland
}

7 June 2019

\begin{abstract}
Brunnermeier et al. (2017a) propose the introduction of sovereign bond-backed securities (SBBS) in the euro area. It and other papers address how the securitisation would insulate senior security holders from actual default-related losses. This article generalises the assessment by using the VAR-based Diebold \& Yilmaz (2012) spillover index methodology to assess potential attenuation of the spillover of shocks in holding-period returns across asset markets from the introduction of SBBS. This is made possible by employing SBBS yields estimated from historical euro area member state sovereign bond yields using Monte Carlo methods, as described in Schönbucher (2003). The econometric results show that (i) SBBS tranching protects senior SBBS holders by reducing the spillover of shocks from the higher-risk peripheral member states to it; (ii) spillovers from high risk sovereigns to a weighted portfolio are much higher than those to the senior SBBS; (iii) a smaller junior SBBS tranche, and the introduction of a mezzanine security, reduces spillover from it to the senior SBBS; and (iv) rolling window analysis indicates that the spillover of shocks from the junior tranche to the senior tranche declines during a period of financial stress. Keywords: Safe Assets; Sovereign Bond Securitisation; Bank-Sovereign Diabolic Loop JEL: C58, G11, G12, G17.
\end{abstract}

Acknowledgments: Views expressed are those of the authors and do not necessarily represent the views of the Central Bank of Ireland or the ESCB. We are grateful to Sam Langfield, Marco Pagano, Richard Portes, Philip Lane, Javier Suárez, Kitty Moloney, Patrick Haran, Angelo Ranaldo and members of the ESRB High-Level Task Force on Safe Assets for helpful comments.

E-mail: dave.cronin@centralbank.ie (Cronin); peter.dunne@centralbank.ie (Dunne) 


\section{Non-Technical Summary}

Brunnermeier et al. (2017b) propose the introduction of sovereign bond-backed securities (SBBS) in the euro area, at least in part, to reduce spillovers across sovereign bond markets owing to localised shocks. Existing simulation results suggest that an important benefit of the tranching associated with SBBS is the degree to which it helps to corral default risks into non-senior securities. Spillovers are important since they have endogenous knock-on effects that could affect a sovereign's ability to roll-over its borrowing. So far, it has not been established whether the proposed securitisation would isolate these important real-time market-based risk exposures of short-term investors in SBBS.

A measure of connectedness and interaction between asset markets can be obtained by application of the Diebold \& Yilmaz (2012) spillover index approach. This provides information on whether asset markets become more or less distinct from one another over time by quantifying the relative importance of own-market shocks and other-market (cross-market) shocks to developments in the markets being considered. A lower spillover index, which arises when own-market shocks are more dominant, indicates a weaker influence of crossmarket shocks, or less interconnectedness.

The objective of the analysis in this paper is to compare the spillovers of shocks between euro area bond markets and SBBS markets. The estimation results represent a lower bound on the potential reduction in spillovers since they are based on a history that does not reflect other SBBS side-effects (e.g., the breaking of the bank-sovereign doom-loop). The evidence suggests that tranching could reduce the overall potential for shocks to be transmitted across markets in periods of financial stress. We find that:

(i) SBBS tranching protects senior SBBS holders by reducing the spillover of shocks from the higher-risk peripheral member states to it;

(ii) spillovers from high risk sovereigns to a weighted portfolio are much higher than those to the senior SBBS;

(iii) a smaller junior SBBS tranche, and the introduction of a mezzanine security, reduces spillover from it to the senior SBBS; 
(iv) rolling window analysis indicates that the spillover of shocks from the junior tranche to the senior tranche declines during a period of financial stress. 


\section{Introduction}

Brunnermeier et al. (2016) and Brunnermeier et al. (2017a) propose the issuance of sovereign bond-backed securities (SBBS) in the euro area with tranches that would be sequentially exposed to losses arising from any defaults on the underlying individual sovereign securities. One of the principal motivations for this proposal is to reduce the potential for spillovers across sovereign bond markets owing to localised shocks as was observed during the euro area sovereign bond crisis of 2009-2012. The authors argue that, in doing so, this initiative also has the potential to reduce self-fulfilling crisis dynamics within euro area sovereign bond markets as has been argued to have happened during the sovereign bond crisis by De Grauwe \& Ji (2013). ${ }^{1}$

These sources of self-fulfilling expectations take on particular importance in the euro area where sovereign debt is not mutualised across the monetary union while the banking system is highly interconnected. Market-based exposures and interdependencies are labeled as endogenous risk by Danielsson \& Shin (2003) and have been further explored in the wake of the Great Financial Crisis by Danielsson et al. (2012) and Ang \& Longstaff (2013). The latter find that both U.S. and European systemic sovereign risk have their roots in financial markets rather than in macroeconomic fundamentals. An implication is that securitisation backed by individual sovereign bonds may be beneficial, not simply in preventing default loss exposures for a subset of investors, but also in suppressing the spread of endogenous risk. By definition, any securitisation that allocates default losses to subordinated tranches will tend to protect some investors - i.e. those holding the more senior tranches - and increase the exposures of others in the event of actual defaults - i.e. those holding the subordinated tranches. ${ }^{2}$ However, actual default events are rare and it is the

1. The European Commission has recently put forward proposals for regulation change to facilitate the emergence of SBBS. This takes as its main influence the proposals made in the report of the ESRB High-Level Task Force on Safe Assets (2018). The draft regulation can be viewed here.

2. Simulated default exercises by Brunnermeier et al. (2017a) show that, in terms of default loss exposures, a $70 \%$ senior tranche is ex post fundamentally safer than any existing individual sovereign bond while the mezzanine and junior tranches will experience expected loss rates comparable to those of euro area sovereigns with intermediate and extreme credit 
changing expectations of such events that affects investment returns in advance of, and even in the absence of, eventual defaults.

The focus in this article is on the extent to which securitisation in euro area sovereign bond markets could reduce the spillover of shocks from one asset market to another. Doing so can prove instructive for such initiatives in the euro area but it should also shed light more generally on the effectiveness of securitisation through tranching. Spillovers are important since they have endogenous knock-on effects to risk taking and investment behaviour. In particular, if the senior tranche of this kind of securitisation is found to be substantially insulated from spillovers, and if banks hold mainly this tranche, then there is the prospect of reducing the negative spiral associated with sovereign risk contagion.

An important advantage of the securitisation approach to breaking the banksovereign nexus is that it could complement regulatory proposals for the treatment of sovereign exposures (RTSE). ${ }^{3}$ Forcing banks to hold a diversified portfolio of European sovereigns could have negative implications for financial stability, as discussed by Wagner (2010). In contrast, if banks were encouraged through regulatory treatment to hold mainly the senior tranche of an SBBS it would protect them from most credit risk shocks arising in the European sovereign market. Since senior security holders are the last SBBS holders to be affected by defaults, it would take a number of big countries defaulting on their issued bonds to have any impact on the value of banks' holdings of the senior securities. This scheme would then effectively break the sovereign-bank doom loop and prevent spillovers to interbank markets due to impaired collateral

\footnotetext{
risks respectively. Increasing the senior tranche proportion beyond $70 \%$ will increase default loss exposure and will eventually produce a credit risk that is greater than that of some low-risk sovereigns (undermining its safe-asset features). Likewise, if the junior tranche proportion becomes too small the junior security will eventually have a greater credit risk than any individual high-risk sovereigns.

3. RTSE ideas have been discussed in a report by the European Systemic Risk Board (2015), a policy insight article by Bénassy-Quéré et al. (2018) and in a recent discussion paper by the Basel Committee on Banking Supervision (2017).
} 
(e.g., as described and modelled in Bolton \& Jeanne (2011) and through the 'bank net worth channel' described by Brunnermeier et al. (2016)). ${ }^{4}$

The Diebold \& Yilmaz (2012) spillover index approach employed here allows a comparison of the interconnectedness among SBBS tranches, and between them and national sovereign bonds (as well as between the latter and an untranched sovereign bond portfolio). The analytical output it provides complements and adds to that of Brunnermeier et al. (2017a) where the attenuation of default loss exposure as a result of SBBS is assessed.

In assessing how securitisation affects interaction in sovereign bond markets, a two-step approach is employed in this article. The first step involves estimating yields on SBBS tranches based on historical national sovereign bond yields. The SBBS yields are estimated using a Monte Carlo estimation method, which is described in Schönbucher (2003). ${ }^{5}$ These estimates have the advantage of retaining the historical features of the time- (and, to some extent, the cross-sectional) dependence among the underlying securities that back the securitisation. The changing correlation of the individual sovereign credit risks (due to heterogeneous fiscal circumstances and varying economic and financial linkages) is captured in the historical behaviour of yield values and accordingly in the SBBS yields.

It should be noted that, because the analysis that follows uses synthetic SBBS yields, estimated using historical yield data, it is only indicative of how investors, and yield dynamics, would behave in practice if SBBS were to be introduced. If the existence of SBBS were to reduce risks due to a weakened bank-sovereign negative feedback loop, the analysis could understate the attenuation in spillovers that would actually occur. On the other hand, were the integrity of the securitisation process undermined (for example, through fraud leading to a detachment of the payments from the SBBS replicating portfolio compared to a weighted portfolio of sovereign bonds), there could be

4. The effects of banks diversifying into the senior tranche of a sovereign bond-backed securitisation, rather than merely diversifying across existing sovereigns, has recently been analysed by Alogoskoufis \& Langfield (2018).

5. We thank colleagues on the ESRB Safe Asset Task Force, Martin Puhl and Thomas Reininger, at the Oesterreichische Nationalbank for technical support in deriving SBBS yields. 
a less favourable outcome than that which is apparent from our calculations. Our analysis addresses neither of these counterfactuals but we regard as modest the likelihood of overstating the benefits. The report of the ESRB Task Force on Safe Assets argues that the issuance process could be made completely bankruptcy-remote from the issuing entity. Regulation and oversight could be instituted to allay fears of any decline in the integrity of the issuance process.

In the second step, spillovers between the SBBS tranches and between them and the national sovereign bonds are measured using the aforementioned Diebold \& Yilmaz (2012) approach. Using VAR-based forecast error variance decompositions, it measures the extent of the spillover of shocks between financial markets by quantifying the relative importance of own-market and cross-market shocks in each asset market with the cross-market share capturing the degree of interconnectedness across markets. The econometric output renders a total spillover index measure and its components. Higher spillover values indicate a stronger influence of cross-market shocks compared to ownmarket shocks. Among the attractions of the Diebold-Yilmaz approach are that one does not have to impose any a priori restriction on which variable has the greater impact on the other, nor does one have to pre-specify particular break points in the data, as can arise with other methodologies aiming to describe financial markets behaviour over time.

Our contribution is novel and unique in applying spillover methodologies to estimated yields of a hypothesised securitisation (to the best of our knowledge, this has never been done before). The econometric results show that SBBS tranching protects senior SBBS holders (including banks) by reducing the spillover of shocks from the higher-risk peripheral member states to it. A smaller junior tranche reduces its spillover to the senior security, ceteris paribus, as does the introduction of a mezzanine security. Rolling window analysis indicates that the spillover of shocks from the junior tranche to the senior tranche declines during periods of financial stress. These results then point to tranching providing a senior SBBS security that protects its holders from shocks elsewhere in the sovereign bond market. 


\section{Yield Estimation and Dataset}

\subsection{SBBS Yield Estimation}

The spillover between SBBS securities can only be assessed if we observe the yields of the SBBS securities. Since these securities did not exist in the past, we rely on estimates based on a simulation approach proposed by Schönbucher (2003) applied to historical sovereign bond yield data. This method was designed to transform market fluctuations in yields of the underlying assets of a securitisation into tranche-specific yield dynamics in a way that reflects the transfer of the sum of specific sovereign credit risks to SBBS tranches according to the subordination of legal claims. The time series properties of, and correlations between, the yields on underlying sovereigns contribute to the dynamics of the estimated SBBS yields. The estimated SBBS yields in this case are not just a linear combination of the underlying securities. A linear model would fully determine the outcomes of our analysis but it would be incapable of preserving the richness of the non-linear dynamics that typically exist among subjectively-held expectations of defaults or that arise from the effects of extreme events (as described in McNeil et al. (2015)).

The steps of the daily SBBS yield estimation approach are as follows;

1. For each day, 30,000 draws are generated from an n-dimensional multivariate random normal (or $\mathrm{t}$ ) distribution with equal pairwise correlations ( $\mathrm{n}$ being the number of sovereign securities). ${ }^{6}$

2. By inverse application of the cumulative normal distribution, each simulated correlated multivariate normal tuple is transformed into a correlated multivariate random standard uniform tuple.

3. The multivariate uniform tuple-members are paired with the $\mathrm{n}$ sovereigns.

6. An n-dimensional correlated multivariate random normal variable is practically achieved by combining $\mathrm{n}$ independent random normals (or $\mathrm{t}$ distributed variables) using a suitably chosen copula (this was done using the MASS-library in R). We set all of the pairwise correlations in the simulation to 0.6 . This was found to frequently produce high enough combined losses to generate spillovers to more senior tranches of the securitisation. 
4. Defaults are simulated according to whether the numbers drawn in the uniform tuple exceed an indicator of the non-default probability in the paired sovereign (the indicator of non-default probability is based on the yield premium over the lowest sovereign yield on the day in question).

5. Where defaults are triggered for a particular simulation, losses for the securitisation are calculated by summing the securitisation-weights of the defaulting sovereigns. ${ }^{7}$ We assume that there is a zero recovery fraction. ${ }^{8}$

6. For each simulation, losses are distributed to the tranches of the securitisation according to the seniority of claims.

7. The means of the distribution of the simulated losses within each of the tranches are used to determine how to distribute the sum of all the yield spreads on the underlying sovereigns observed that day.

8. Yield levels for the different tranches of the securitisation on each day are then calculated as the estimated yield-spreads added to the lowest yield among the underlying sovereigns.

In this way, probable daily yields on the SBBS components for two different securitisation structures are generated over an almost 17-year historical period (January 2000 to October 2016) without the need for a structural modelling of the complex dependencies among the underlying sovereigns (e.g. as in Lucas et al. (2017)). The first is a two-tier 70:30 structure involving a 70\% senior security and a $30 \%$ subordinated security that we refer to as the junior security.

7. The weights determining how much each sovereign contributes to the collateral that backs the securitisation are based on the 'ECB Capital Key' adjusted for our sample. We include eleven sovereigns with the following weights: Austria 2.89, Belgium 3.65, Finland 1.85, France 20.86, Germany 26.48, Greece 2.99, Ireland 1.71, Italy 18.11, the Netherlands 5.89, Portugal 2.57, and Spain 13.01.

8. This is an extremely high Loss Given Default (LGD) rate historically. Cruces \& Trebesch (2013) suggest LGD for sovereign defaults is typically below 50\%. However, given that our simulations might not be able to generate enough clustered extreme outcomes we have used the more extreme LGD assumption to ensure losses regularly affect the non-junior tranches. The average losses in the simulations that exceed the junior tranche fraction determine the reallocation of yield premiums from the sovereigns (summed) to the more senior tranches of the SBBS. Sovereigns with higher credit risk will be the ones that turn out to be the most frequently defaulting in our simulations because they have the highest yield spreads. We consider sensitivity to simulation parameters in section 3.5. 
The second is a three-tier 70:20:10 structure in which there is a division of the subordinated tranches into a $20 \%$ mezzanine tranche and a $10 \%$ junior tranche. ${ }^{9}$ Beyond the basic differentiation of a junior tranche and a senior tranche in the two-tranche case, a three-way tranching would provide greater investment options to potential purchasers and, thus, might be easier to market. The $10 \%$ junior tranche was selected for its ability to generate spillovers to the mezzanine tranche while at the same time providing some diversification of exposure to small-country defaults. In the second step, these series allow an analysis of the return dependencies among the tranches of the securitisation to be estimated and compared with the return dependencies among the 11 individual national sovereign bonds (or representative subsets) that were involved in simulating the SBBS yields.

The estimated yield-spreads for the tranches of the securitisation (derived by following steps 5 to 7 ) are simply added to the lowest sovereign yield and the lowest yield acts as a base that is expected to be proximate to a zero default probability. ${ }^{10}$

Some further detail on some of the steps above is warranted. In step 3, the nondefault probability for a given day and given sovereign is proxied by 1 minus the sovereign yield in excess of the lowest sovereign yield. For example, a yield that is 200 basis points above the lowest sovereign yield on a given day would proxy for a 0.02 likelihood of default and a simulated default would be triggered if the paired number drawn from the uniform distribution exceeds 0.98 (i.e. exceeds the proxy for probability of not defaulting $=1.00-0.02) .^{11}$

We acknowledge that the default probability proxy is not a perfect reflection of default likelihood. Yield spreads are known to be indicative of risk-neutral probabilities and, therefore, are a combination of risk aversion, physical default

9. We retain the terminology 'junior' rather than 'equity' for the most junior claim since this is not envisaged as being held by the originating agent.

10. The proxies for default likelihood may be biased upwards when there is an information shock that disproportionately reduces the lowest yielding sovereign due to safe-haven status. We accept this bias since it makes it even more likely to find spillovers to the senior tranche and harder to support the null hypothesis that tranching attenuates such spillovers.

11. The yield spread is the spread between the annualised yields to maturity and therefore implies that this spread proxies the annualised default likelihood over the life of the bond. 
probabilities and additional imperfections arising from the presence of liquidity premia and safe-haven discounts (see Hull et al. (2005) for a more detailed discussion of these imperfections). Three aspects of our approach help to ensure that enough defaults are simulated and that high enough losses on the senior tranche give a realistic representation of senior yields. First, the yield spread for each sovereign is calculated as the deviation from the sovereign bond that has the lowest yield on a given day. The lowest yielding sovereign during the crisis was most often the German Bund (or one of the other core euro area countries). Such safe haven assets will generally have a lower yield than that on a riskfree asset because they provide more protection to investors in crisis periods (Hull et al. (2005) adjusts spreads over T-Bill rates for exactly this reason). Using spreads over a safe haven asset, therefore, produces an upwardly biased estimate of the likelihood of default. Secondly, the size of losses from defaults matters to the likelihood that investors in the senior tranches of an SBBS experience losses. In our simulation, these losses are maximised by assuming a loss given default of $100 \%$. As mentioned above, this is much larger than is likely if historical default losses are a good guide to outcomes from future default events. Finally, we use a very highly correlated multivariate process to trigger defaults in our simulations so that multiple simultaneous defaults arise and produce higher aggregate losses that are more likely to spill over to senior tranches.

\subsection{History versus a modelled counterfactual}

Overall, we expect the estimated yields of the tranches of the securitisation to be a reasonable representation of what would transpire in a re-run of history assuming the securitisation has little impact on the structure of sovereign yield dynamics. A counterfactual analysis that controls for potential future changes in the structure of sovereign bond markets with the introduction of SBBS is beyond the scope of this study. The results presented here are nevertheless informative as they indicate how such securities would interact with each other, and with existing sovereign markets, under the diverse range of historical conditions experienced over the 2000 to 2016 period, including the pre-2008 period, the period of financial crisis in the wake of the Lehman Brothers default, the euro area sovereign debt crisis of 2009-2012, and the subsequent 
gradual improvement in euro area sovereign bond markets - particularly those of peripheral member states. Unconventional monetary policy involving large scale purchases of EU sovereign bonds - that could have compromised liquidity - was also exercised during the sovereign debt crisis (through the Securities Markets Programme) and for much of the latter part of the sample period (in the form of the Expanded Asset Purchase Programme). ${ }^{12}$

One can conjecture that several structural changes from SBBS issuance could arise. A possible structural effect would be a reduction in the liquidity of the smaller sovereign bond markets (as described in a recent contribution by Leandro \& Zettelmeyer (2018)). This could occur, but it is doubtful that it would be any more severe than the reduced liquidity of such markets during the ECB's Securities Markets Programme (SMP) or its Expanded Asset Purchase Programme (EAPP). Also, the findings of the ESRB Task Force on Safe Assets, particularly the contribution by Dunne (2019), imply that the existence of SBBS provides a conduit for positive liquidity externalities. ${ }^{13}$

Another concern is that there could be a fast dry-up in demand for junior claims during stressed times and this could impair the plentiful supply of senior tranches just when they are needed. Leandro \& Zettelmeyer (2018) lay out conditions that would make this less likely and all of these are practically achievable. Essentially, such effects can be attenuated if the securitisation process is managed effectively and transparently (including with regard to what is included as collateral in new issuances during a crisis). Since this hypothetical scenario is not part of the history used for estimation of SBBS yield premiums, we would acknowledge that the estimate of the yield spread on the junior tranche used here could suffer from some downside bias.

It remains the case however, that holding even the junior tranche during a crisis provides a certain degree of protection from isolated defaults among the more

12. Unlike the case of SBBS issuance, the unconventional monetary policy action did not replace bonds purchased with similar assets, so the liquidity effects of SBBS issuance are likely to be less severe.

13. It demonstrates that dealers could hedge their positions in specific bond markets using off-setting positions in liquid SBBS markets. It also shows that dealers who hedge and diversify across different markets would be able to substantially reduce risks associated with providing liquidity across the entire European sovereign debt market. 
crisis-prone sovereigns and this is likely to be attractive for some categories of investors. Analysis provided in section 1.5 of the Report of the ESRB HighLevel Task Force on Safe Assets (2018) (see, page 57 of Volume II) shows that investment in the junior tranche is rewarded with a yield premium (based on the same simulation as used in this work) that is very competitive using metrics such as Sharpe ratios.

Counteracting the various negative externalities are the substantial positive effects associated with a larger stock of safe assets that would absorb flights-tosafety and flights-to-liquidity with less dramatic price effects than is currently the case. As described in Brunnermeier \& Huang (2018), SBBS would also divert destabilising cross-country capital flows to the benefit of all member states. Finally, it would reduce risks due to the breaking of the sovereignbank doom loop (since banks would be encouraged to hold the much safer and less connected senior tranche of SBBS rather than their own country's sovereign bonds). These positive effects from the issuance of SBBS (that, in turn, are likely to reduce the type of endogeneous risks identified by Danielsson \& Shin (2003)) are not present in the historical analysis and their effects are, therefore, not reflected in the yield estimation and spillover analysis. Without these positive externalities, our estimates of yield premiums would be positively biased. Overall, it is difficult to model or assess the likely balance between beneficial and maligned structural effects of SBBS issuance. Instead, we provide evidence below that spillovers are significantly attenuated among SBBS under the very wide range of circumstances in the historical data that we use.

\subsection{Data}

The sample under analysis extends from 10 January 2000 to 31 October 2016. Panels A and B of Figure 1, respectively, depict the time series behaviour of yields on SBBS securities under the two alternative tranching assumptions (70:30 and 70:20:10) while panel $\mathrm{C}$ shows yields of a selection of individual sovereigns. To provide a perspective on how securitisation differs from diversification effects, the first two panels also include the yield on a portfolio of euro area sovereigns termed the weighted portfolio (where, as described in footnote 7 , the portfolio weights are based on the proportional 
National Central Bank contributions to the ECB's capital). The period of the European sovereign debt crisis is highlighted in all graphs and extends from November 2009, when the Greece government indicated its 2009 deficit-to-GDP projection was being revised upward from 5\% to 12.7\%, to August 2012, which concluded a six-month period when the ESM treaty was signed (February 2012), the second Greece adjustment programme was adopted (March 2012), and ECB President Mario Draghi indicated that the central bank would do "whatever it takes" to ensure the proper functioning of monetary policy (August 2012).

It is immediately apparent from panels A and B that the 70:20:10 securitisation gives rise to a junior tranche with a much more elevated yield during the sovereign debt crisis than is the case for the same tranche under the 70:30 structure. This is a result of a greater concentration of risks within the much smaller junior tranche in the 70:20:10 securitisation and reflects how concentrated shocks are across the underlying securities. It also reflects the securitisation having a GDP-based weighting and the largest historical shocks occurring among the smaller sovereigns.

As well as comparing spillovers among 70:30 and 70:20:10 securitisations in section 3, these two SBBS structures are considered relative to the spillover that occurs between national sovereign bond markets and the untranched portfolio. This uses historical 10 year yields for 11 euro area countries (namely; Austria (AT), Belgium (BE), Finland (FI), France (FR), Germany (DE), Greece (GR), Ireland (IE), Italy (IT), the Netherlands (NL), Portugal (PT), and Spain (ES)) and the portfolio is constructed using weights based on ECB capital contributions as described in footnote 7. Panel $\mathrm{C}$ shows that Greece bonds had a very large yield premium during the crisis while the other individual sovereigns shown in that panel have similar yield behaviours to at least one of the SBBS tranches. 


\section{Diebold-Yilmaz Methodology and Results}

\subsection{Spillover Methodology}

The Diebold-Yilmaz methodology is used to measure the extent of spillovers of shocks across a portfolio of assets. This method relies on forecast error variance decompositions provided by vector autoregression (VAR) estimations applied to times series data. It utilises the generalised VAR framework of Koop et al. (1996). The variance decomposition output is used to produce a total spillover index and spillover components. The relative contributions of own-variable shocks and cross-variable shocks to the variance of the forecast error for all variables in the VAR are provided. These shares can be displayed in tabular or graphical form. The Diebold-Yilmaz methodology is outlined in algebraic form in the appendix.

The spillover index approach is applied initially, in turn, to the eleven euro area country data set, to the senior and junior securities associated with the 70-30 tranching structure, and to the senior, mezzanine and junior securities with the 70-20-10 tranching structure. Using weekly intervals, the 10-year yields for each tranche less the EONIA interbank interest rate provides spread values. First-differences of these spreads are used (over the period 10 January 2000 to 31 October 2016) for the econometric estimation. A VAR lag length of four is chosen based on Akaike-information and Schwartz-Bayesian criteria while the forecast horizon is ten weeks. ${ }^{14}$

\subsection{Full Sample Estimation of Spillover Index and Components}

Tables 1, 2 and 3 provide the full sample (i.e. 10 January 2000 to 31 October 2016) estimates of the spillover index and its components for the eleven countries, the 70-30 tranche case and the 70-20-10 tranche case, respectively. Each row in a table provides the forecast error variance decomposition for the

14. We can report that the decompositions are not sensitive to VAR lag lengths from one to six, and to forecast horizons of eight weeks to twelve weeks. 
variable indicated in the first cell of that row, with the decomposition shares adding to $100 \%$. The sum of the off-diagonal entries (the cross-variance shares) gives the gross spillover from other assets and is shown in the column marked "From others". The total spillover index (TSI) is the average of the entries in that column and its value is shown in the bottom row of the table. ${ }^{15}$ In calculating the average cross-variance share per variable, it provides a summary indicator of average spillovers across the asset markets under consideration, be that the two or three tranches, or eleven countries.

The "Contribution to others" values in the third last row of each table are the sum of the off-diagonal elements in each column for the variable indicated in the first cell of the column and each entry indicates that asset's gross spillover to all other markets. The difference in value between an asset's entry in the "Contributions to others" row and its entry in the "From others" column gives a measure of net spillover between it and other assets (shown in the final column of the table). Finally, the individual off-diagonal elements indicate the spillover from one asset to another, as opposed to the cumulative gross and net spillover values provided in the right-hand-side and bottom rows of the table.

Table 1 shows the own-shocks effects for each of the eleven member states included in it on the diagonal entries of the table. These are strongest for Greece (at $65.2 \%$ ), which indicates its sovereign bond market being largely detached, or decoupled, from the other euro area member states. The off-diagonal entries on the Greece column and row indicate it having little interaction with other sovereign bond markets. The diagonal entries of all other member states are in a range of $12.4 \%$ (France) to $21.9 \%$ (Portugal). By corollary, those member states have a higher degree of interaction with one another than arises between Greece and other member states. These tend to be relatively evenly spread across countries (with the aforementioned exception of Greece). So, for example, looking at the entries in the row for Spain in Table 1, it has spillovers from other member states ranging from $6.6 \%$ (Portugal) to $12.1 \%$ (Italy). In the column for Spain, and again ignoring the Greece entry in that column, its spillovers to other member states are in a range of $7.6 \%$ to $11.3 \%$. The total spillover

15. The TSI can also be calculated as the average of the "contribution to others" row of the table, its entries summing to the same value as that in the "from others" column. 
index (TSI) - that is the average total spillover to, or from, member states is $81.1 \%$.

Table 2 indicates a low average spillover (a TSI value of 29.5\%) among the senior and junior tranches with a 70-30 structure than arises among the eleven member states. In turn, in the "From Others" column, the gross spillovers from the other asset are broadly similar in value and close to the average indicated by the TSI. The net spillovers are just above $1 \%$.

The full sample spillover values among the senior, mezzanine and junior tranches (the 70-20-10 structure) are shown in Table 3. In this case, the average spillover is much higher, with a TSI value of $46.1 \%$. The values in the "From others" columns are in a wider range than arises in Table 2, with the junior tranche having the lowest spillover from others at $40.3 \%$, followed by the senior tranche at $44.1 \%$ and the mezzanine tranche at $54 \%$. The same ordering occurs in the "Contribution to others" row (values of $29.7 \%, 39.6 \%$ and $69 \%$ ). The mezzanine security then has the highest spillovers to- and from-other assets. In terms of net spillover, the senior security is a net recipient from others (at $4.5 \%$ ), while the mezzanine asset is a net transmitter of spillovers to the other two assets (an absolute value of 15\%). The junior tranche has a net spillover value of $10.6 \%$.

From the perspective of minimising the spillover of shocks from the junior to the senior tranche, the most important feature of Tables 2 and 3 is how the spillover from the junior tranche to the senior tranche is much lower in the latter (at $7 \%$ ) compared to the former (at 28.7\%). Thus, a three-way tranching of SBBS, while increasing average (i.e. TSI) spillover values, insulates the senior security more from shocks to the most junior security. A question that follows is whether this reduction in spillover is owing to the junior tranche having a lower weighting (at 10\%, as opposed to 30\%) in the three-tranche case and/or the three-way (as opposed to two-way) tranching. This is considered in Tables 7 and 8 and in Figure 5 below.

Tables 4, 5 and 6 expand on Table 1 to include, in turn, the weighted single portfolio of sovereign bonds, the 70-30 securities, and the 70-20-10 securities alongside the eleven national bonds. Table 4 shows that the spillovers from the periphery member states (GR, ES, IE, IT, PT) to the weighted portfolio 
are much higher than what they impart to the senior security in Tables 5 and 6. The spillovers from each of the periphery member states to the senior tranche can also be seen to be marginally lower or unchanged in the 70-20-10 case than in the 70-30 case. Accordingly, the data indicate tranching acting to protect the senior security holders from developments in the peripheral member states.

\subsection{Rolling Window Spillover Index and Components Estimation}

A rolling-window estimation permits an examination of how spillover, or interaction, among the assets develops over time. Figures 2, 3 and 4 use 200week rolling windows, with the first window having an end-date of 3 November 2003 and the last window having 31 October 2016 as its final observation. The number of windows estimated is 679 .

The TSI values over time for the eleven countries, the 70-30, and the 70-2010 asset combinations are shown in Figure 2. As per the full-sample tables, the two-asset case records lower TSI values than the three-asset case over all windows. The gap between the two widens marginally during the crisis period and remains greater in the post-crisis period than before the crisis. The average spillover values among the 11 national sovereign bond markets are much higher in each estimation window than when the yields from the 70-30 and 70-20-10 tranches are used.

Figure 3 shows the gross and net spillovers for the 70-30 tranche structure. As with the entries for this pairing in Table 2, the gross spillovers to the senior and junior securities in panel (A) are broadly in line with one another over time. Both decline substantially during the crisis period from values of over $40 \%$ at its start to close to $20 \%$ by its end. An economic interpretation of this development is that financial market stress leads to the senior and junior securities being seen by investors as more distinct from one another. This is in line with the stylised features of safe assets as outlined and modelled in the work of Caballero \& Farhi (2017) and Moreira \& Savov (2017). The gross spillover values move in a narrow, low-value range after the crisis. Panel (B) of 
Figure 3 indicates low net spillover values (usually no more than $5 \%$ in absolute value) between the senior and junior tranches in the 70-30 structure.

Figure 4 covers the three-asset, 70-20-10 structure. The gross-spillover-fromothers values are shown in the panels on the left-hand-side of that figure. In all three charts, the total gross spillover values have a downward trend over time. This decline is strongest for the senior tranche (panel (A)). The other two lines in that panel represent the spillover to the senior from the mezzanine and from the junior tranches, as indicated in the panel's labelling. There is a larger spillover to the senior security from the mezzanine security than from the junior security.

Looking across all three panels on the left-hand-side of Figure 4, the gross spillovers to and from the senior security fall over time. The level of the bidirectional interaction between the mezzanine and the junior securities, as measured by gross spillover values, is maintained during the latter part of the crisis and after it. These developments can be interpreted as the senior security becoming relatively detached from the other two securities during the crisis and remaining so in its wake.

As with the table comparisons, even though the TSI is higher across all windows in the 70-20-10 case, the gross spillover of shocks from the junior to senior tranche is lower in the three-tranche case (Figure 4, panel (a)) than in the twotranche case (Figure 3, panel (a)). Prior to the crisis, the spillover of shocks is some 18 to 22 percentage points higher in the two-tranche case, peaking at $26 \%$ early in the crisis (in September 2010). Thereafter, the spillover differential between the two cases declines over time, reaching a low of about 1 percentage point in October 2015 before widening again (reaching 11 percentage points in the final window). The three-tier tranche case then involves the junior security's spillover to the senior security being lower through all windows but more noticeably so during the crisis period. ${ }^{16}$

16. The spillover differential during the crisis period ranges from $14 \%$ to $26 \%$. 


\subsection{Comparison of spillovers to senior tranche under different cases}

In the previous sub-section, it was shown that spillovers from the junior to the senior tranche are lower in the three-tranche (70-20-10) case than in the two tranche (70-30) case. Likewise, spillovers from the peripheral member states to the senior security are lower in the three-tranche case than in the two-tranche case. Alternative weightings of the two-tranche securities are used for the fullsample spillover estimates in Tables 7 (80-20) and 8 (90-10). Comparing those two tables to Table 2, it can be seen that a smaller junior tranche results in a lower spillover of shocks from it to the senior security, falling from $28.7 \%$ in Table 2 to $22.3 \%$ and $16.9 \%$ in Tables 7 and 8 , respectively. The junior security also has a $10 \%$ weighting in Table 3, where a three way tranching occurs, and the spillover from junior to senior security is lower again, at $7 \%$. Figure 5 confirms this to be the case for the 2009-12 crisis, as well as for most non-crisis windows.

The rolling-window estimation approach can also be used to assess how different weightings between tranches matter to spillovers from national sovereign bonds to the senior tranche. Spillovers across 200-week windows from Greece to the senior tranche are assessed in the context of a two-tranche SBBS issue. In the first instance, the thirteen-variable system of Table 5 is estimated on a rolling window basis. The spillover from Greece to the senior (70\% weighting) across all windows is shown in Figure 6, panel (A). The alternative two-tranche cases (80-20 and 90-10) were then substituted for the 70-30 pairing in two further estimations of the thirteen-variable case and the new rolling estimations were undertaken. Finally, the twelve-variable case of Table 4 is also estimated on a rolling window basis (where there are eleven member state bonds and the weighted portfolios). The spillovers from Greece to the senior security in each of these cases is shown in Figure 6, panel (A). The chart shows that spillovers are higher from Greece to the weighted portfolio across all windows, while its spillover to the senior security is not sensitive to different weightings of the SBBS structure between senior and junior securities.

Panel (B) of Figure 6 shows two of the spillover series from panel (A) (those from Greece to the $70 \%$ senior security and from Greece to the weighted 
portfolio) and the spillover from Greece to Germany from a rolling window estimation of the eleven member state system of Table 1 (where Germany can be viewed as the safest asset). As with panel (A), spillover to the senior, $70 \%$ security is lower throughout all windows compared to Germany (if only marginally so for many of the later windows) emphasising how tranching reduces spillover values from relatively risky assets through both periods of crisis and non-crisis.

\subsection{Sensitivity tests}

In this sub-section, we consider the sensitivity of the results reported in subsection 3.4 on two fronts. First of all, we look at some of the econometric modelling choices made for the baseline cases (window size, periodicity of the data, the assumption about the contemporaneous correlation of shocks utilised). Secondly, we consider sensitivities to how the yield data for the securitisation is generated. In particular, we consider the cases where the Gaussian-based simulation is replaced with a t-distributed variant (where a degrees of freedom of 1 is assumed for the marginals in the multivariate correlated t-distribution) and where different correlation values are used in the default triggering process.

So, in the first instance, using the 70-20-10 tranche data, we reduce the size of the window used for the rolling estimations from 200 weeks to 100 weeks and also to 50 weeks. Using shorter windows (and daily data below) may help address the possibility that there could be greater movements in spillovers at higher frequencies due to, for example, variation in liquidity. The TSIs for all three are plotted in Figure 7. These show little variation in the TSIs in the pre-crisis and crisis periods but, surprisingly perhaps, some variation in the post-2012 period. This is particularly so for the 50-week case where a shorter window size would leave the TSI more susceptible to the vagaries that can arise in data over the short term. In Figure 8, daily 70-20-10 spread data are used. The TSI in this case has similar quantitative values and qualitative behaviour to its weekly counterpart (see Figure 2) in the pre-crisis and crisis periods. There is, again, considerable variation in the post-crisis period. 
The baseline spillover index is estimated using a generalised forecast error variance decomposition. An alternative is to use orthogonalised decompositions where the ordering of the variables in the VAR matters as to when individual variable shocks take effect on the other variables. In the case here, the ordering chosen allows shocks to the junior to contemporaneously affect the mezzanine and senior variables while shocks to the mezzanine and senior tranches only affect the junior tranche with a one-period delay. Likewise, shocks to the mezzanine contemporaneously affect the senior with only lagged feedback. This is consistent with the underlying rationale for, and tranching of, SBBS whereby the subordinate securities would be expected to exercise stronger effects on the senior securities than would arise the other way around. The plot of the orthogonalised TSI in Figure 9, however, differs little from that of the generalised TSI (which is copied from Figure 2).

Looking beyond the choices made in the econometric analysis, we can consider variants of the yield estimation. In the previous estimations we use SBBS yield data (for both 70-30 and 70-20-10 tranche options) generated using a Gaussian-based simulator where the normal marginal distributions are used for the multivariate random draws. In this case, the probability of tail events is quite low, and once the normal draws are translated to their uniformly distributed variants (by applying the inverse of the cumulative normal density), this produces fewer simulated defaults than might be expected in reality (recall that the $\left[\begin{array}{ll}0 & 1\end{array}\right]$ uniform draw produces defaults only when it exceeds 1 minus the default probability measure). An alternative is to simulate defaults by generating default triggers using a multivariate t-distribution in the first stage of the simulation process. The t-distribution has much fatter tails so tail events are much more likely. This will generate more defaults when the correlated multivariate t-distributed draws are translated to their uniform counterparts. Both panels of Figure 10, however, show that only small differences in TSI arise between the Gaussian and t-distribution cases.

The simulation procedure in the baseline two-tranche and three-tranche cases uses a $60 \%$ correlation in the default triggering process. Yields based on a much lower correlation in the triggering process (of 5\%) were estimated for both tranching options. Panels (A) and (B) of Figure 11 indicate spillovers being marginally higher in the higher correlation case during the crisis period 
of 2009-12. For the two-tranche case, the gap continues well into the post-crisis period. The difference, however, is not large. Future research may be warranted to allow for regime changes in the correlation of default triggering conditions as described in Das et al. (2001). To the extent that sovereign yield spreads have time-varying correlations, the existing analysis, nevertheless, already reflects a significant amount of the clustering and correlation in default likelihood.

\section{Conclusion}

Sovereign bond-backed securities (SBBS) have recently been espoused as financial market instruments that could address safe asset shortages and excessive bank-sovereign linkages in the euro area. The arguments for such securitisation and the form it could take have been outlined in Brunnermeier et al. (2016) and Brunnermeier et al. (2017a). Existing assessments of how effective the proposal would be in generating safe assets merely address how the securitisation would insulate senior security holders from actual defaultrelated losses. This article generalises the assessment by examining how the spillover of shocks within secondary markets would be attenuated (i.e. how the spillovers among investment returns on holdings of bonds/SBBS assets would be affected).

Given the aims of the SBBS proposal, the analysis suggests some desirable benefits arising from it. First, spillovers from the higher-risk peripheral member states to the senior security of a two-tranche or three-tranche case are lower than what arises from those member states to a weighted portfolio (i.e. notranching) case. The rolling window analysis indicates that spillovers from the junior to the senior also decline substantially during a period of financial crisis. Thus, if the main purpose of senior SBBS is to protect their holders from shocks in other markets, the results indicate it doing so.

The main caveat is that the historical bond data from which the SBBS yields are derived can only be regarded as indicative of what would happen under similar levels of stress in the future. How investors and securitisers would react in a crisis when SBBS assets exist is not known. The actual outcome would likely be some mixture of potential positive and negative externalities resulting 
from SBBS issuance. The positive externalities from the breaking of the banksovereign doom loop, and the reduction of endogeneous risks that this produces, would most likely reduce risk and spillover generally.

It is also possible that the analysis based on historical data (when SBBS were absent) does not adequately reflect the beneficial effects that would flow from SBBS investors being better able to match their risk preferences with their ex ante risk exposures. Being aware in advance of how losses would be allocated in the case of a downturn, or period of stress in bond markets, is likely to be valuable to investors. Knowing that the senior asset of the securitisation is protected from most losses - regardless of where shocks are located - affords the investor the opportunity to avoid such exposures at the outset. For investors willing to take higher risk, there is an opportunity to gain estimable exposures for an observable yield premium when investing in the junior (and/or mezzanine) SBBS.

The negative externalities are mostly linked with fears of an unexpected selective default in the midst of a crisis or some disruptive operational risk incident, perhaps linked with fraudulent activities by the agents responsible for issuance. These types of risk can only be counteracted by clear and transparent management of the issuance process. Every known contingent risk in the management of SBBS issuance then needs to be accounted for and the response to crisis situations agreed to in advance. Our analysis does not reflect the possible role of such risks. However, while these occurrences could disrupt the gross flow of new SBBS, the stock of SBBS outstanding would remain positive for a period determined by the average duration of the outstanding stock. Benefits from the redirection of flight-to-safety flows would then remain for a period that is likely to last until the peak of the crisis has passed and until new issuance recovers.

Future research could try to take account of the different types of counterfactual realities that could arise with SBBS in place. For example, with a larger supply of safe assets (the senior SBBS), there is less likely to be a strong flight-tosafety effect remaining in individual sovereign bond yield dynamics. This could be reflected in SBBS yield spread estimation by giving relatively more weight to safer individual sovereigns in the SBBS estimation. Likewise, if SBBS issuance was to be halted by a crisis it would be possible to identify whether existing 
issued SBBS would continue to deliver benefits at a declining rate as they mature. Future research could also consider use of non-linear copula-models of credit risk and extreme shocks, with McNeil et al. (2015) arguing for such models as better tools for modelling extreme events, as well as applying the analysis to other geographical areas that might benefit from SBBS. ${ }^{17} 18$

17. One approach to identifying tail risk spillover is dealt with in the ESRB Safe Asset Task Force report and in a related paper that utilises dynamic value-at-risk and marginal expected shortfall metrics (see De Sola Perea et al. (2018)).

18. Brunnermeier \& Huang (2018) propose SBBS backed by emerging market economy sovereign bonds. 


\section{Appendix: Diebold-Yilmaz Methodology}

The construction of the Diebold and Yilmaz spillover index relies on forecast error variance decompositions, which show the proportion of the movement in a variable's development over time due to its own shocks and that due to shocks in other variables in the vector autoregression. The spillover index quantifies the proportion of the total variance forecast due to the cross-variable shocks. The baseline decompositions here rely on a generalised VAR framework, which has the implication that variance decompositions are invariant to the ordering of the variables in the VAR.

The $N$-variable $\operatorname{VAR}(\mathrm{p})$ specification is:

$$
x_{t}=\sum_{i=1}^{p} \Phi_{i} x_{t-i}+\epsilon_{t}
$$

Where $x$ is a vector of variables and $\epsilon \sim(0, \Sigma)$ is a vector of independently and identically distributed disturbances.

Assuming covariance stationarity, this can be rewritten in moving average form as:

$$
x_{t}=\sum_{i=1}^{\infty} A_{i} \epsilon_{t-i}
$$

Where the $N \times N$ coefficient matrices $A_{i}$ observe the recursion $A_{i}=\phi_{1} A_{i-1}+$ $\phi_{2} A_{i-2}+\cdots+\phi_{p} A_{i-p}$, with $A_{0}$ an $N \times N$ identity matrix and $A_{i}=0$ for $i<0$. The fraction of the $\mathrm{H}$-step-ahead error variance in forecasting $x_{i}$ owing to shocks to $x_{j}$, for all $j \neq i$, for each $i$ is measured and provides the basis for the variance decompositions.

Cross-variance spillovers are the fractions of the $H$-step-ahead error variance in forecasting $x_{i}$ owing to shocks to $x_{j}$, for $i, j=1,2, \ldots, N$, such that $i \neq j$, while own variance spillovers are the fractions of the $H$-step-ahead error variance in forecasting $x_{i}$ owing to shocks to $x_{i}$, for $i=1,2, \ldots, N$. With the $H$-stepahead forecast error variance decompositions denoted as $\theta_{i j}^{g}(H)$ for $\mathrm{H}=1,2, \ldots$, then

$$
\theta_{i j}^{g}(H)=\frac{\sigma_{i i}^{-1} \sum_{h=0}^{H-1}\left(e_{i}^{\prime} A_{h} \Sigma e_{j}\right)^{2}}{\sum_{h=0}^{H-1}\left(e_{i}^{\prime} A_{h} \Sigma A_{h}^{\prime} e_{j}\right)}
$$


Where $\Sigma$ is the variance matrix for the error vector $\epsilon, \sigma_{i i}$ is the standard deviation of the error term for the $i^{\text {th }}$ equation and $e_{i}$ is the selection vector with one as the $i^{\text {th }}$ element and zeros otherwise.

Each entry of the variance decomposition matrix is normalised by the sum of the elements of each row of the variance decomposition table as:

$$
\widetilde{\theta}_{i j}^{g}(H)=\frac{\theta_{i j}^{g}(H)}{\sum_{j=1}^{N} \theta_{i j}^{g}(H)}
$$

By construction, $\sum_{j=1}^{N} \widetilde{\theta}_{i j}^{g}(H)=1$ and $\sum_{i, j=1}^{N} \widetilde{\theta}_{i j}^{g}(H)=N$.

The total spillover index is then defined as:

$$
\widetilde{\theta}_{i j}^{g}(H)=\frac{\theta_{i j}^{g}(H)}{\sum_{j=1}^{N} \theta_{i j}^{g}(H)}
$$

The directional spillover from all other variables $j$ to variable $i$ is measured as:

$$
S_{i .}^{g}(H)=\frac{\sum_{j=1(j \neq i)}^{N} \widetilde{\theta}_{i j}^{g}(H)}{\sum_{j=1}^{N} \widetilde{\theta}_{i j}^{g}(H)} .100
$$

Likewise, the directional spillover from market $i$ to all other markets $j$ is calculated as:

$$
S_{. i}^{g}(H)=\frac{\sum_{j=1(i \neq j)}^{N} \widetilde{\theta}_{j i}^{g}(H)}{\sum_{j=1}^{N} \widetilde{\theta}_{j i}^{g}(H)} .100
$$

The net volatility spillovers from market $i$ to all markets $j$ can be calculated as the difference between gross volatility shocks transmitted to and gross volatility shocks received from all other markets:

$$
S^{g}(H)=S_{i .}^{g}(H)-S_{. i}^{g}(H)
$$




\section{References}

Alogoskoufis, S. \& Langfield, S. (2018), 'Regulating the Doom Loop', ESRB Working Paper Series No 74.

Ang, A. \& Longstaff, F. A. (2013), 'Systemic Sovereign Credit Risk: Lessons from the U.S. and Europe', Journal of Monetary Economics 60(5), 493-510.

Basel Committee on Banking Supervision (2017), The regulatory treatment of sovereign exposures, Discussion paper.

Bénassy-Quéré, A., Brunnermeier, M., Enderlein, H., Farhi, E., Fratzscher, M., Fuest, C., Gourinchas, P.-O., Martin, P., Pisani-Ferry, J., Rey, H., Schnabel, I., Véron, N., Weder di Mauro, B. \& Zettelmeyer, J. (2018), 'Reconciling Risk Sharing with Market Discipline: A Constructive Approach to Euro Area Reform', CEPR Policy Insight No. 91.

Bolton, P. \& Jeanne, O. (2011), 'Sovereign Default Risk and Bank Fragility in Financially Integrated Economies', IMF Economic Review 59(2), 162-194.

Brunnermeier, M. K., Garicano, L., Lane, P. R., Pagano, M., Reis, R.,

Santos, T., Thesmar, D., Van Nieuwerburgh, S. \& Vayanos, D. (2016), 'The Sovereign-Bank Diabolic Loop and ESBies', American Economic Review Papers and Proceedings 106(5), 508-512.

Brunnermeier, M. K. \& Huang, L. (2018), 'A Global Safe Asset For and From Emerging Market Economies', NBER Working Paper No. 25373.

Brunnermeier, M. K., Langfield, S., Pagano, M., Reis, R., Van Nieuwerburgh, S. \& Vayanos, D. (2017a), 'ESBies: Safety in the Tranches', Economic Policy 32(90), 175-219.

Brunnermeier, M. K., Langfield, S., Pagano, M., Reis, R., van Nieuwerburgh, S. \& Vayanos, D. (2017b), 'ESBies: Safety in the Tranches', Economic Policy 32(90), 175-219.

Caballero, R. \& Farhi, E. (2017), 'The Safety Trap', The Review of Economic Studies 85(1), 223-274. 
Cruces, J. J. \& Trebesch, C. (2013), 'Sovereign Defaults: The Price of Haircuts', American Economic Journal: Macroeconomics 5(3), 85-117.

Danielsson, J. \& Shin, H. S. (2003), 'Endogenous Risk. in, "Modern Risk Management: A History," edited by Peter Field, 297-314. London: Risk Books'.

Danielsson, J., Shin, H. S. \& Zigrand, J. (2012), 'Endogenous and Systemic Risk, chapter 2 in "Quantifying Systemic Risk" by Joseph G. Haubrich and Andrew W. Lo, editors, University of Chicago Press'.

Das, S. R., Fong, H. G. \& Geng, G. (2001), 'Impact of Correlated Default Risk on Credit Portfolios', Journal of Fixed Income 11(3), 9-19.

De Grauwe, P. \& Ji, Y. (2013), 'Self Fulfilling Crises in the Eurozone: An Empirical Test', Journal of International Money \& Finance 34, 15-36.

De Sola Perea, M., Dunne, P., Puhl, M. \& Reininger, T. (2018), 'Sovereign bond-backed securities: a VAR for VaR and Marginal Expected Shortfall Assessment', ESRB Working Paper Series No 65.

Diebold, F. \& Yilmaz, K. (2012), 'Better to Give than to Receive: Predictive Directional Measurement of Volatility Spillovers', International Journal of Forecasting 28(1), 57-66.

Dunne, P. G. (2019), 'Positive Liquidity Spillovers from Sovereign Bond-Backed Securities', Journal of Risk and Financial Management 12(2), 1-25.

ESRB High-Level Task Force on Safe Assets (2018), 'Sovereign bond-backed securities: A feasibility study', European Systemic Risk Board.

European Systemic Risk Board (2015), Report on the regulatory treatment of sovereign exposures.

Hull, J., Predescu, M. \& White, A. (2005), 'Bond Prices, Default Probabilities and Risk Premiums', Journal of Credit Risk 1(2), 53-60.

Koop, G., Pesaran, M. \& Potter, S. (1996), 'Impulse Response Analysis in Non-linear Multivariate Models', Journal of Econometrics 74(1), 119-147.

Leandro, A. \& Zettelmeyer, J. (2018), 'The Search for a Euro Area Safe Asset.', CEPR Discussion Paper No. 12793. 
Lucas, A., Schwaab, B. \& Zhang, X. (2017), 'Modelling Financial Sector Tail Risk in the Euro Area', Journal of Applied Econometrics 32, 171-191.

McNeil, A. J., Frey, R. \& Embrechts, P. (2015), Quantitative Risk Management: Concepts, Techniques and Tools, Princeton university press, Princeton NJ.

Moreira, A. \& Savov, A. (2017), 'The Macroeconomics of Shadow Banking', Journal of Finance 72(6), 2381-2431.

Schönbucher, P. J. (2003), Credit Derivatives Pricing Models: Models, Pricing and Implementation, Wiley, London.

Wagner, W. (2010), 'Diversification at Financial Institutions and Systemic Crises', Journal of Financial Intermediation 19(3), 373-386. 


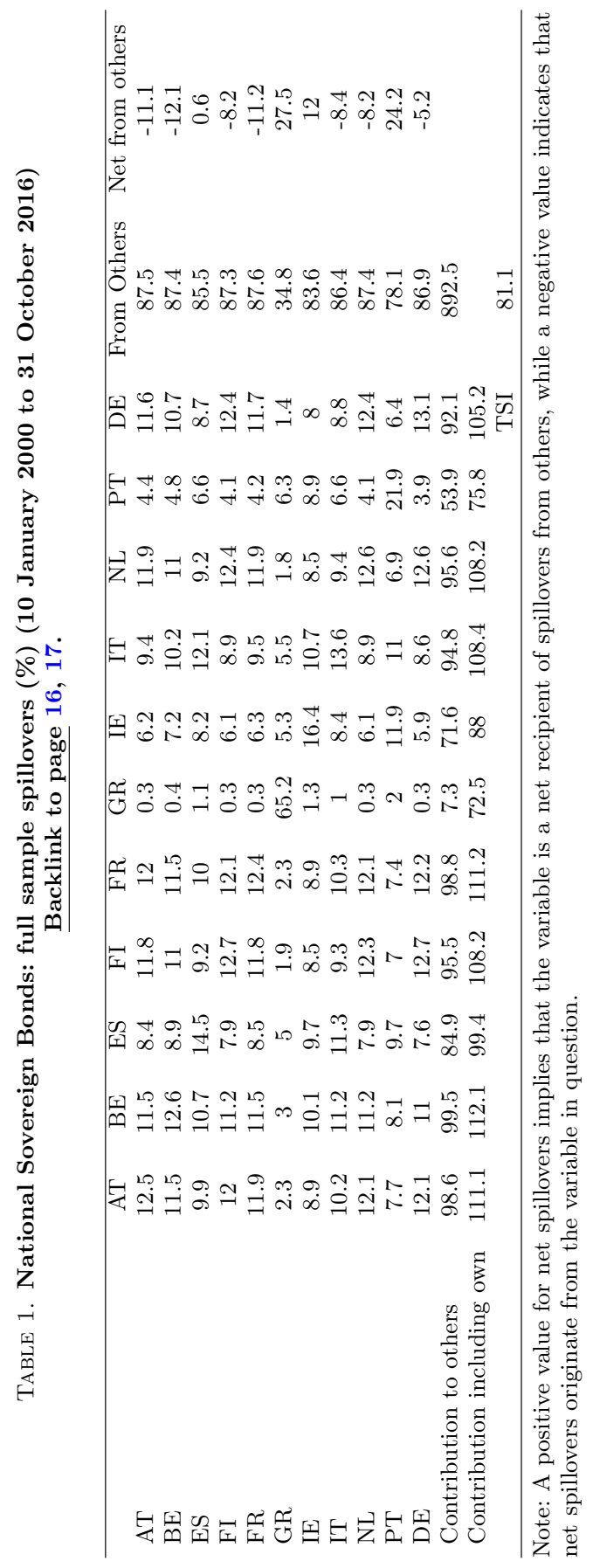


TABLE 2. Seventy-Thirty tranche: full sample spillovers (\%) (10 January 2000 to 31 October 2016)

Backlink to page 16, 18.

\begin{tabular}{lcccc}
\hline & Senior & Junior & From others & Net from others \\
Senior & 71.3 & 28.7 & 28.7 & 1.4 \\
Junior & 30.1 & 69.9 & 30.1 & -1.4 \\
Contribution to others & 30.1 & 28.7 & 58.9 & \\
Contribution including own & 101.4 & 98.6 & & \\
& & TSI & 29.5 & \\
\hline
\end{tabular}

Note: A positive value for net spillovers implies that the variable is a net recipient of spillovers from others, while a negative value indicates that net spillovers originate from the variable in question.

TABLE 3. Seventy-Twenty-Ten tranche: full sample spillovers (\%) (10 January 2000 to 31 October 2016)

Backlink to page 16, 18.

\begin{tabular}{lccccc}
\hline & Senior & Mezzanine & Junior & From others & Net from others \\
Senior & 55.9 & 37 & 7 & 44.1 & 4.5 \\
Mezzanine & 31.3 & 46 & 22.7 & 54 & -15 \\
Junior & 8.3 & 32 & 59.7 & 40.3 & 10.6 \\
Contribution to others & 39.6 & 69 & 29.7 & 138.4 & \\
Contribution including own & 95.5 & 115 & 89.4 & & \\
& & & TSI & 46.1 & \\
\hline
\end{tabular}

Note: A positive value for net spillovers implies that the variable is a net recipient of spillovers from others, while a negative value indicates that net spillovers originate from the variable in question. 


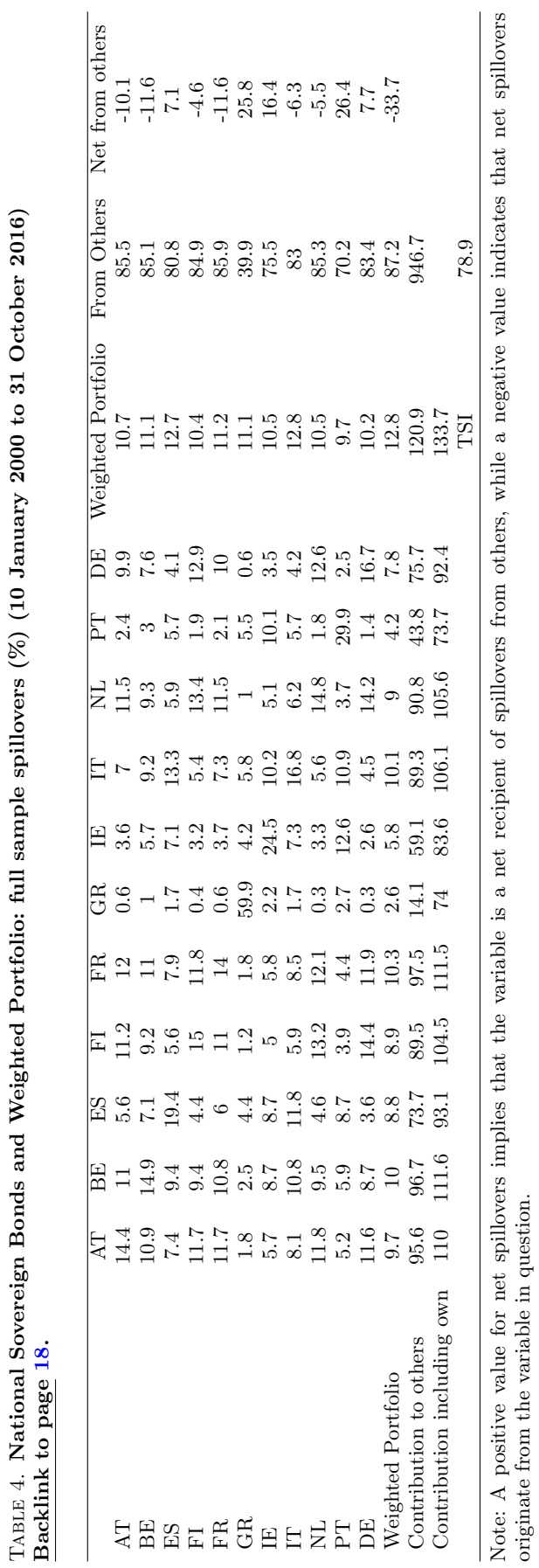




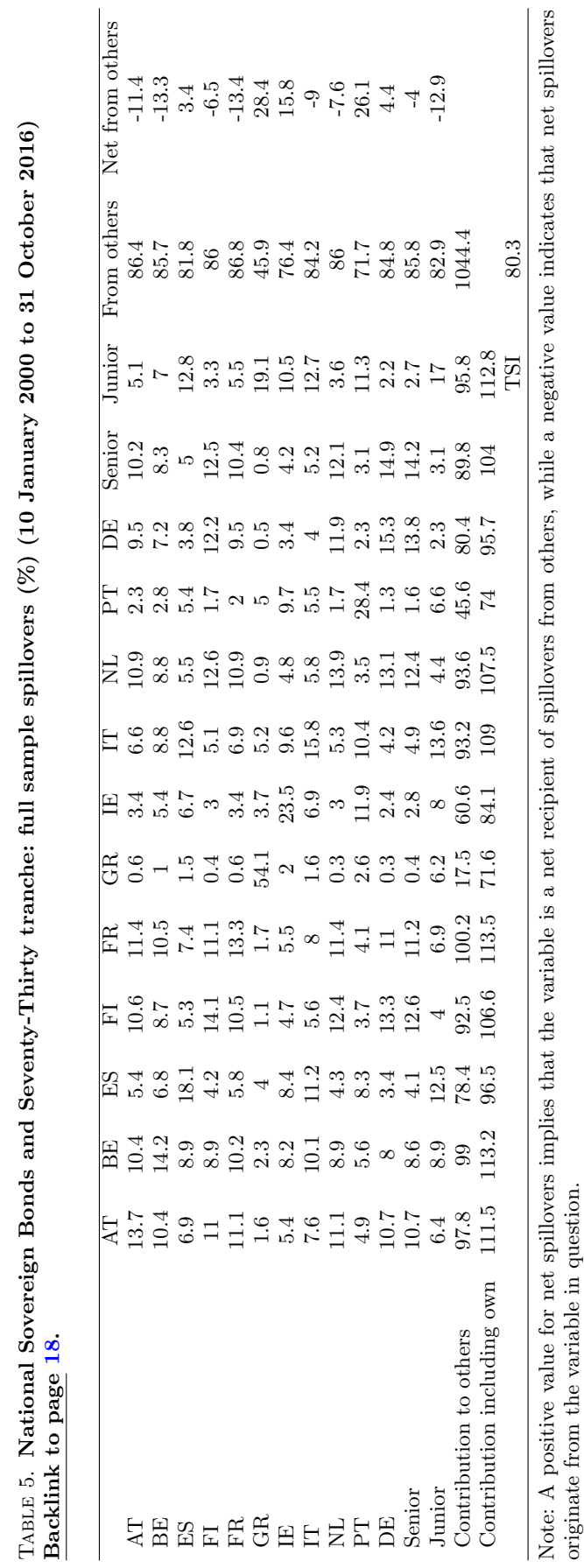




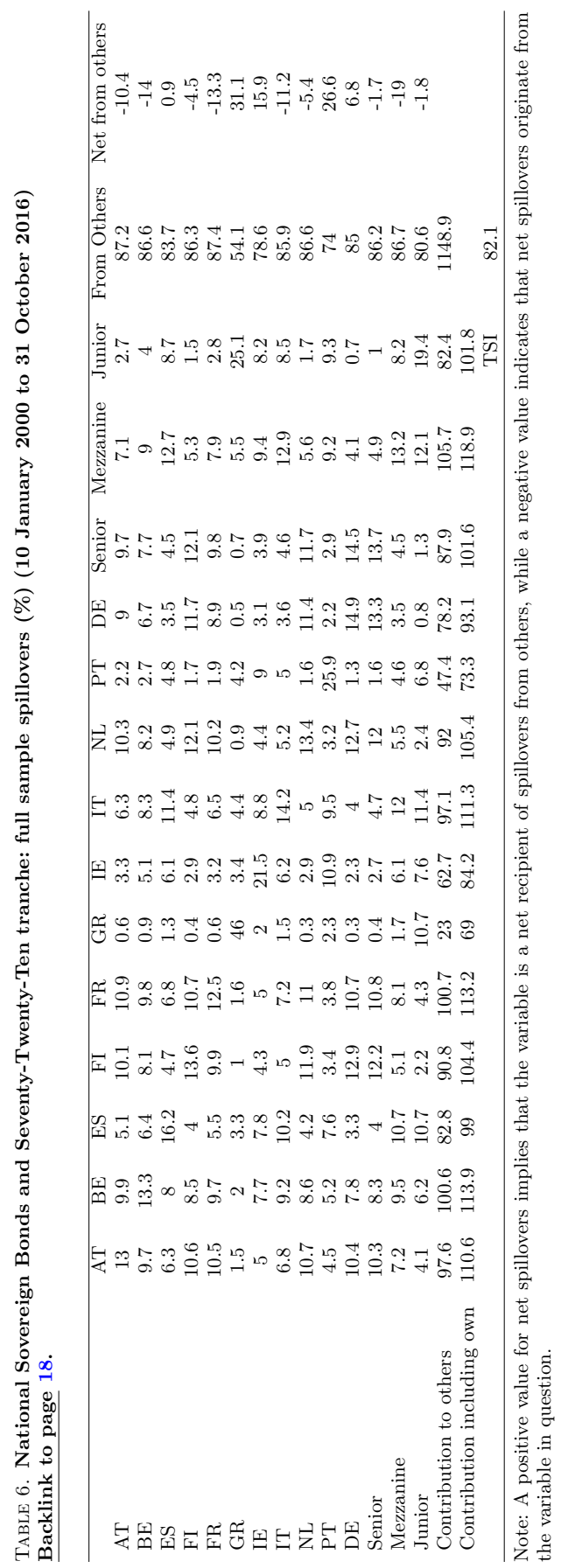


TABLE 7. Eighty-Twenty tranche: full sample spillovers (\%) (10 January 2000 to 31 October 2016)

Backlink to page 18.

\begin{tabular}{lcccc}
\hline & Senior & Junior & From others & Net from others \\
Senior & 77.7 & 22.3 & 22.3 & 1.5 \\
Junior & 23.8 & 76.2 & 23.8 & -1.5 \\
Contribution to others & 23.8 & 22.3 & 46.1 & \\
Contribution including own & 101.5 & 98.5 & & \\
& & TSI & 23.1 & \\
\hline
\end{tabular}

Note: A positive value for net spillovers implies that the variable is a net recipient of spillovers from others, while a negative value indicates that net spillovers originate from the variable in question.

TABLE 8. Ninety-Ten tranche: full sample spillovers (\%) (10 January 2000 to 31 October 2016)

Backlink to page 18.

\begin{tabular}{lcccc}
\hline & Senior & Junior & From others & Net from others \\
Senior & 83.1 & 16.9 & 16.9 & 1.5 \\
Junior & 18.4 & 81.6 & 18.4 & -1.5 \\
Contribution to others & 18.4 & 16.9 & 35.3 & \\
Contribution including own & 101.5 & 98.5 & & \\
& & TSI & 17.6 & \\
\hline
\end{tabular}

Note: A positive value for net spillovers implies that the variable is a net recipient of spillovers from others, while a negative value indicates that net spillovers originate from the variable in question. 
Figure 1. Estimated Yields on SBBS Tranches \& Selected Sovereigns (\%). Backlink to page 14 .

(A) 70:30 SBBS Yields

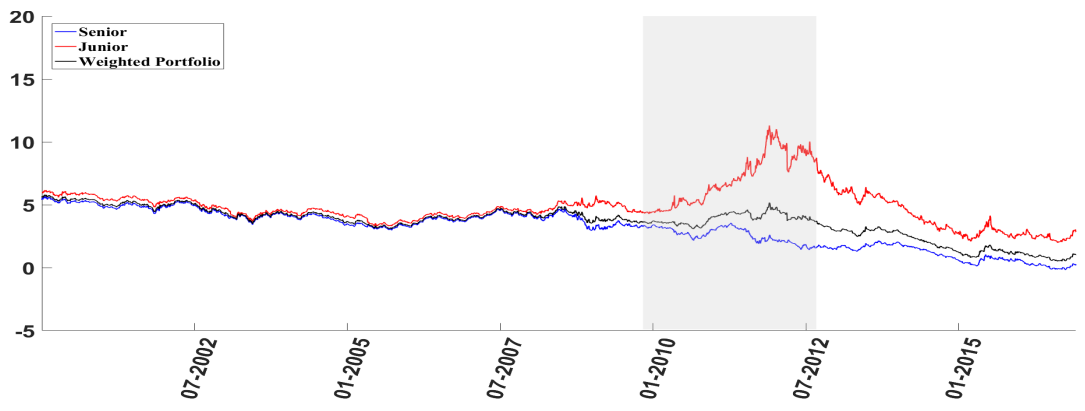

(B) 70:20:10 SBBS Yields

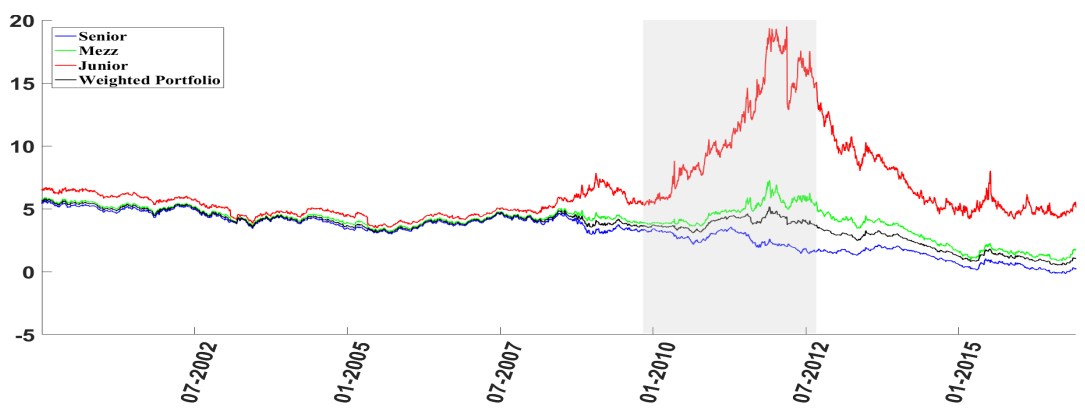

(c) Yields of DE, IT, GR \& PT

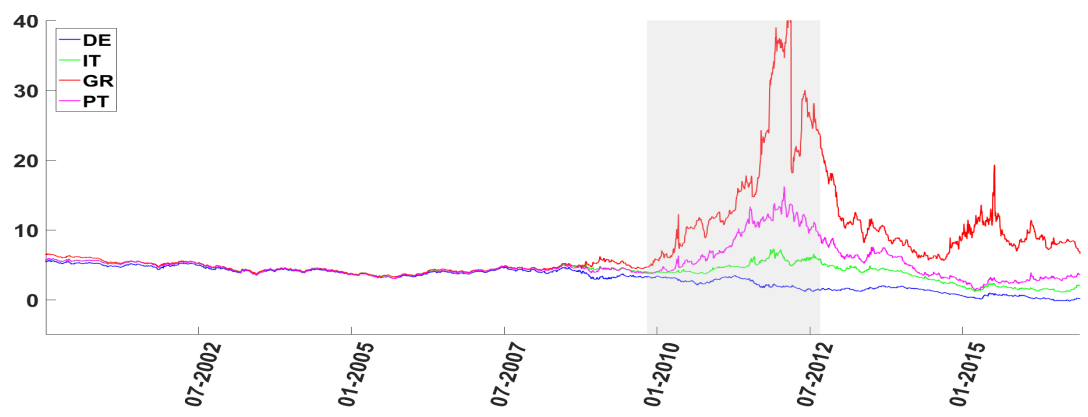

Note: Shaded area is euro area sovereign bond crisis period (November 2009-August 2012). 


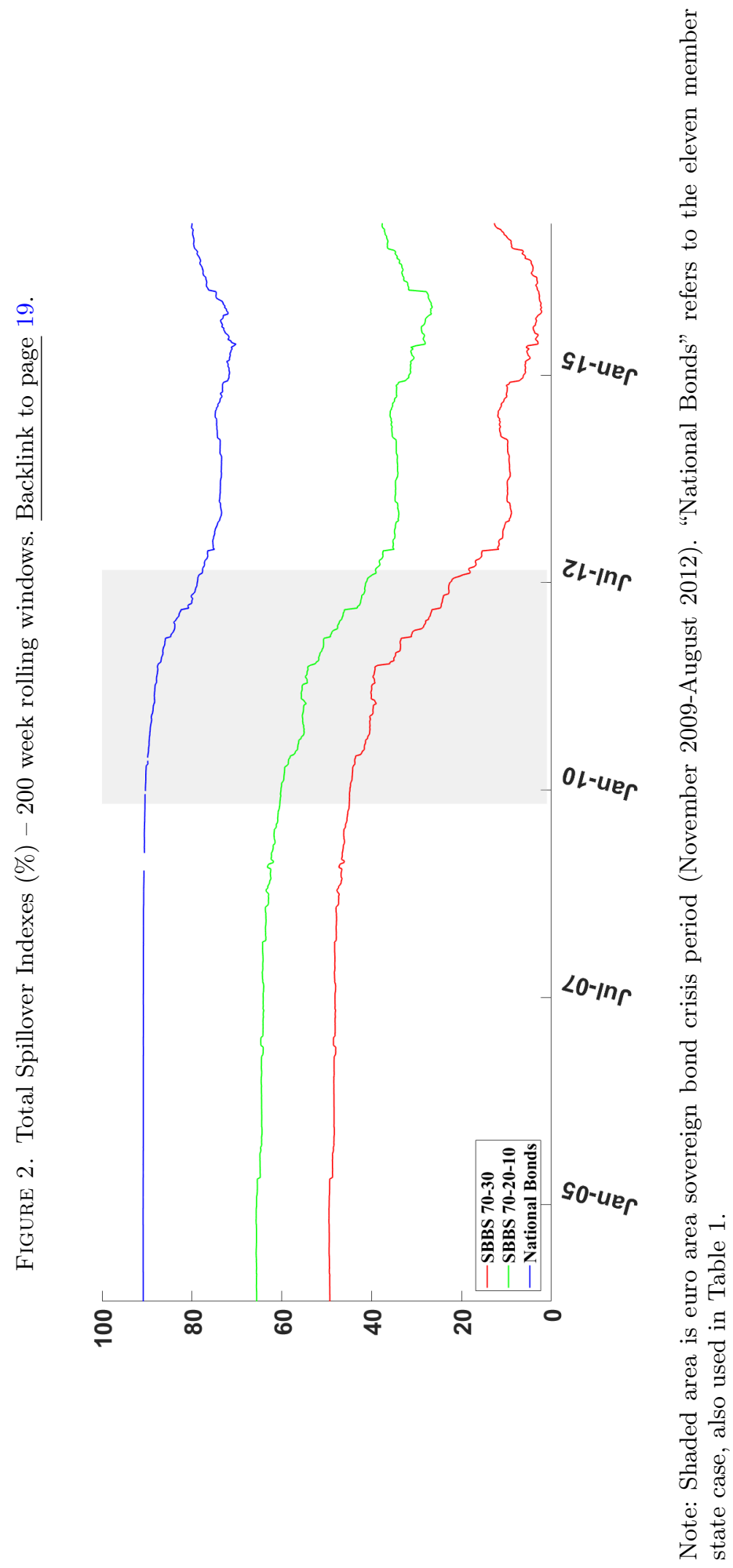




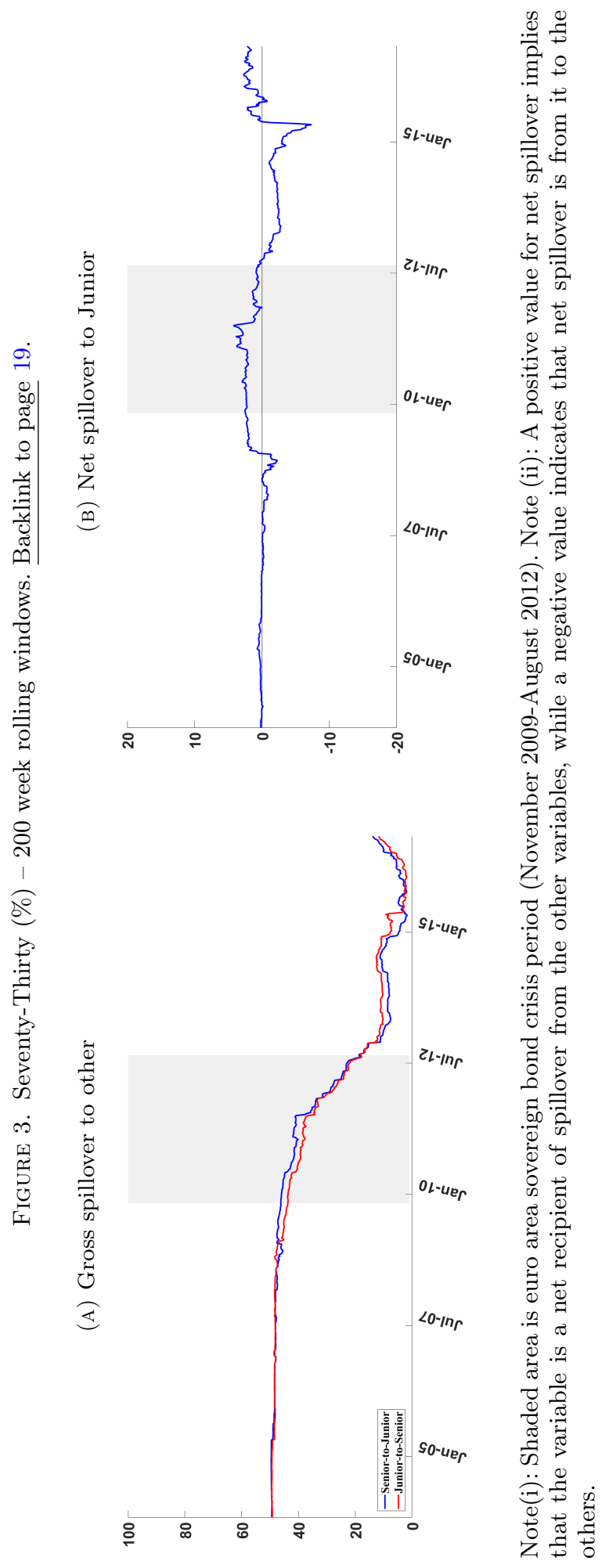


Figure 4. Seventy-Twenty-Ten (\%) - 200 week rolling windows . Backlink to page 20, 20 .

(A) Gross spillover to Senior

(B) Net spillover to Senior

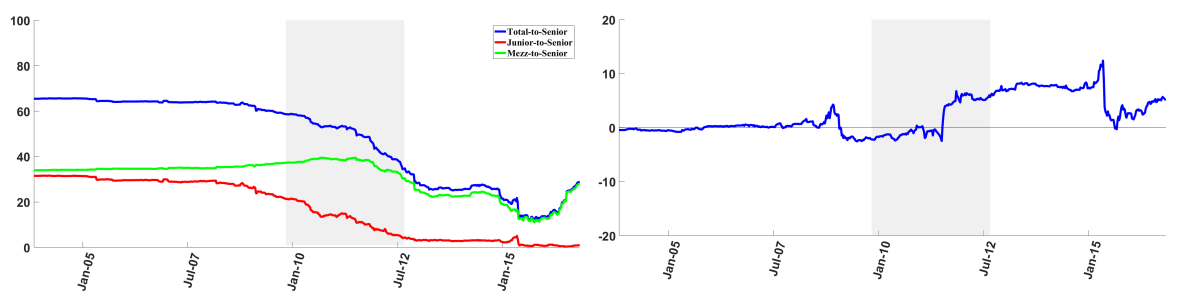

(c) Gross spillover to Mezzanine

(D) Net spillover to Mezzanine

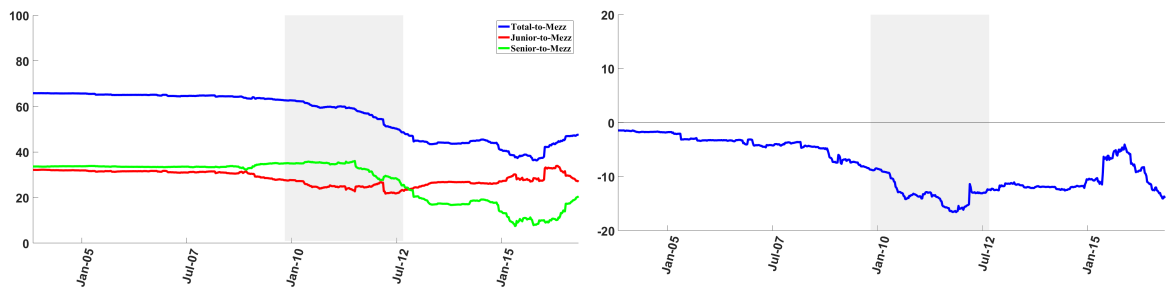

(E) Gross spillover to Junior

(F) Net spillover to Junior

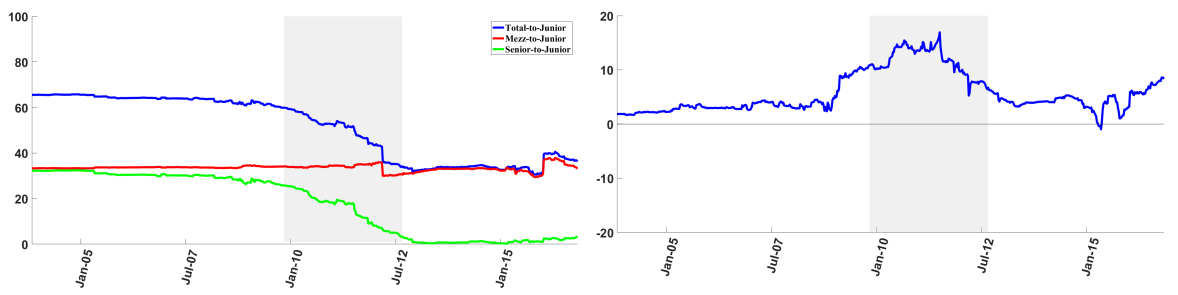

Note(i): Shaded area is euro area sovereign bond crisis period (November 2009-August 2012). Note (ii): A positive value for net spillover implies that the variable is a net recipient of spillover from the other variables, while a negative value indicates that net spillover is from it to the others. 
42

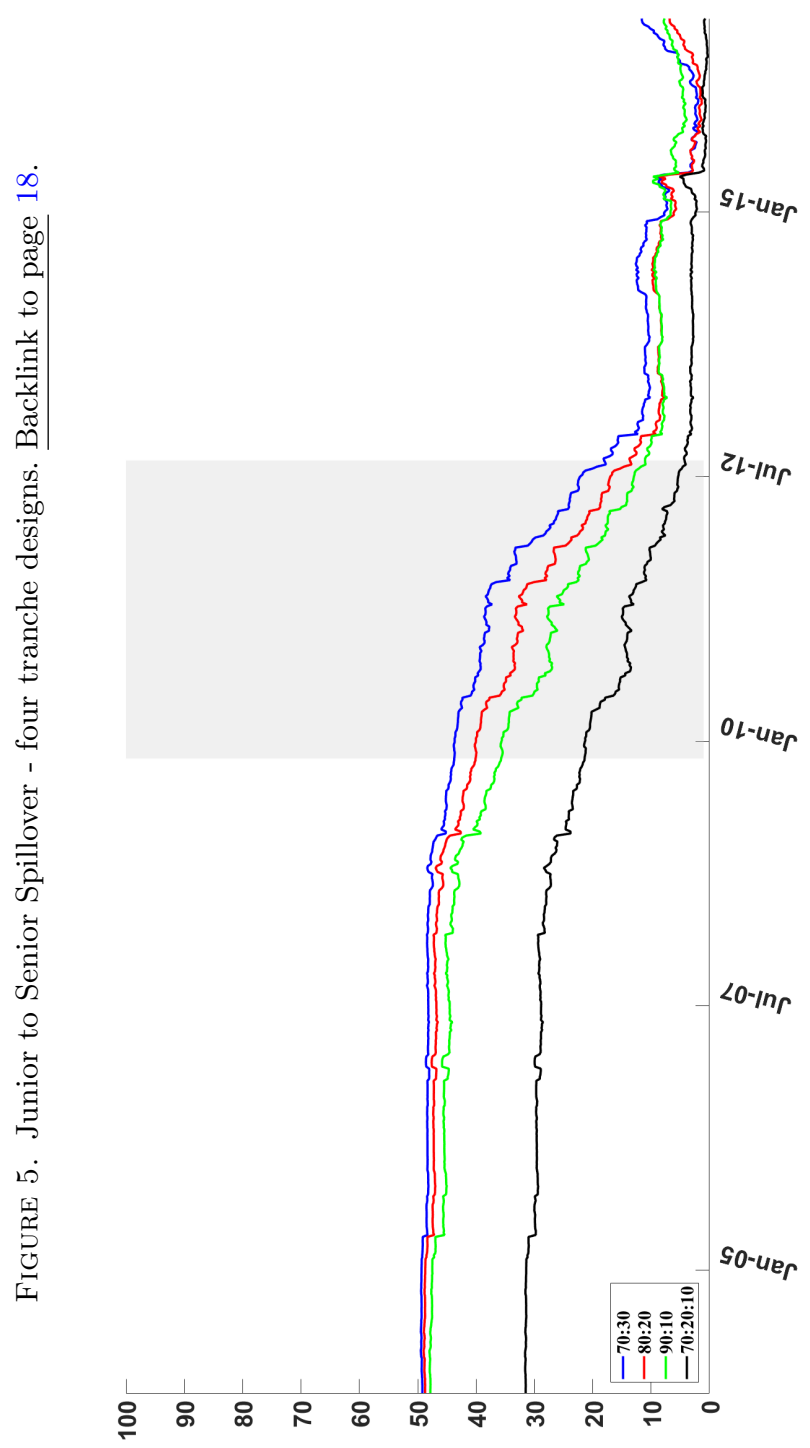

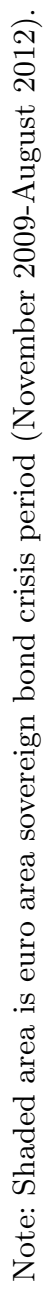




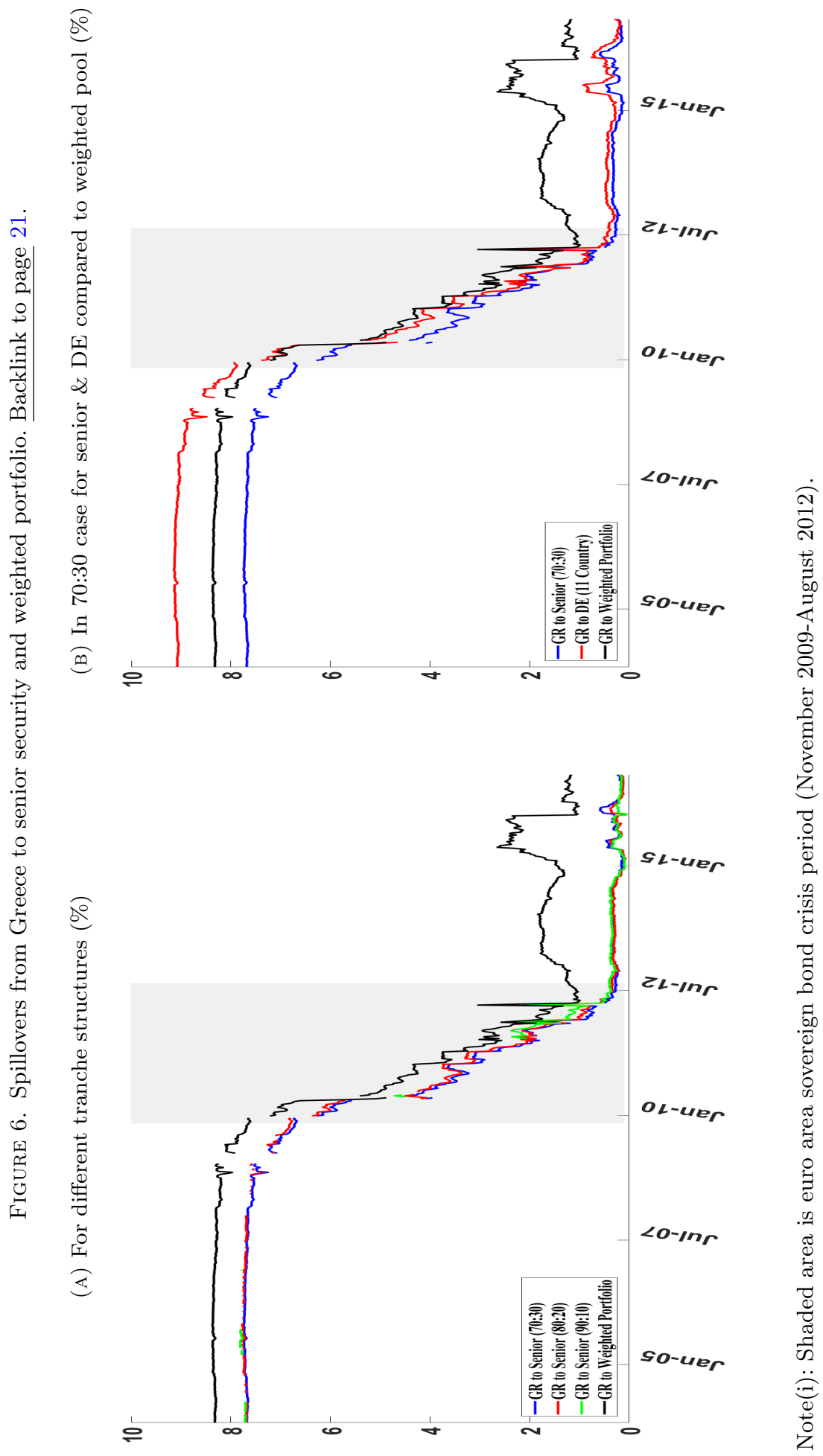




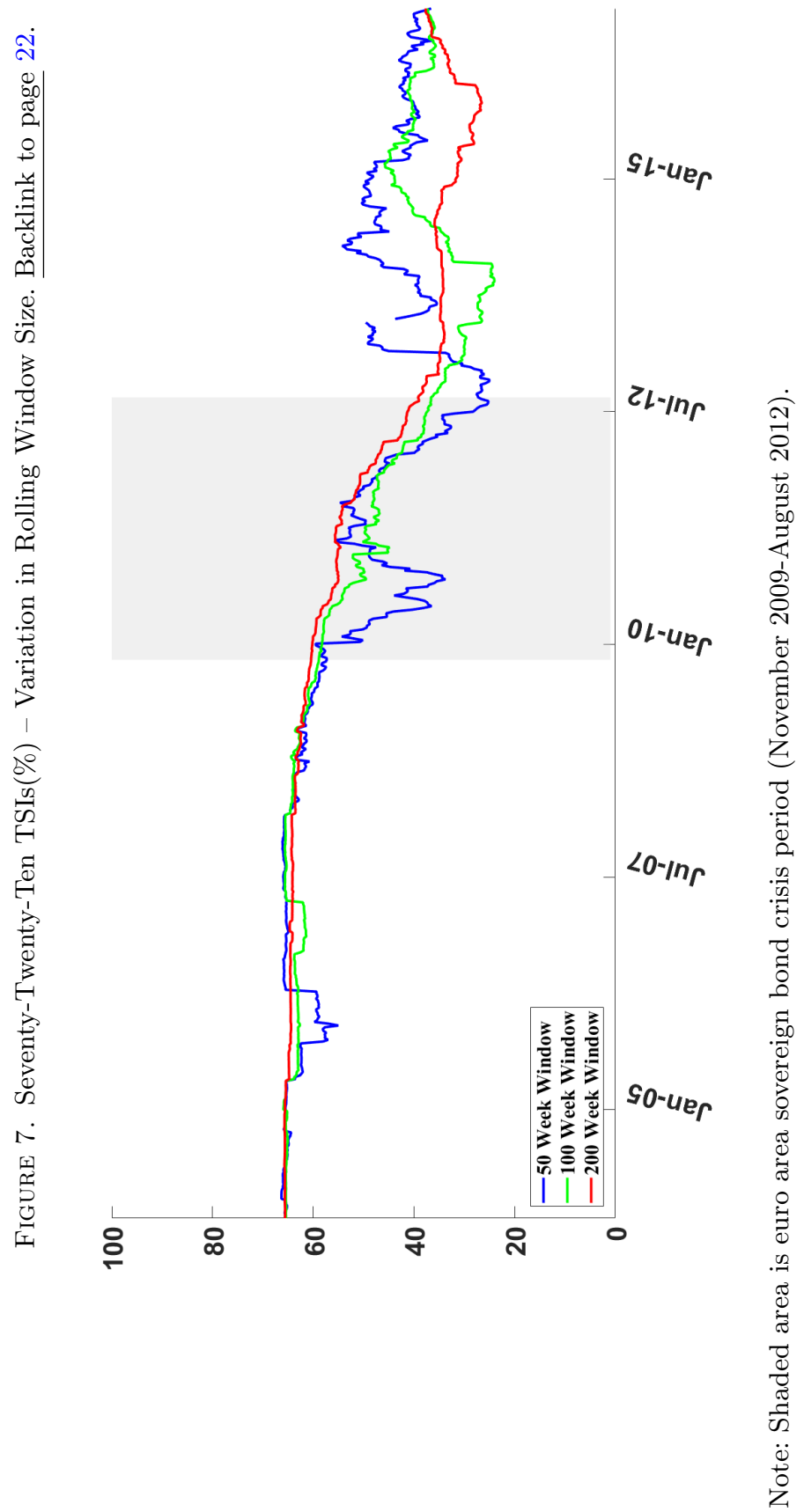




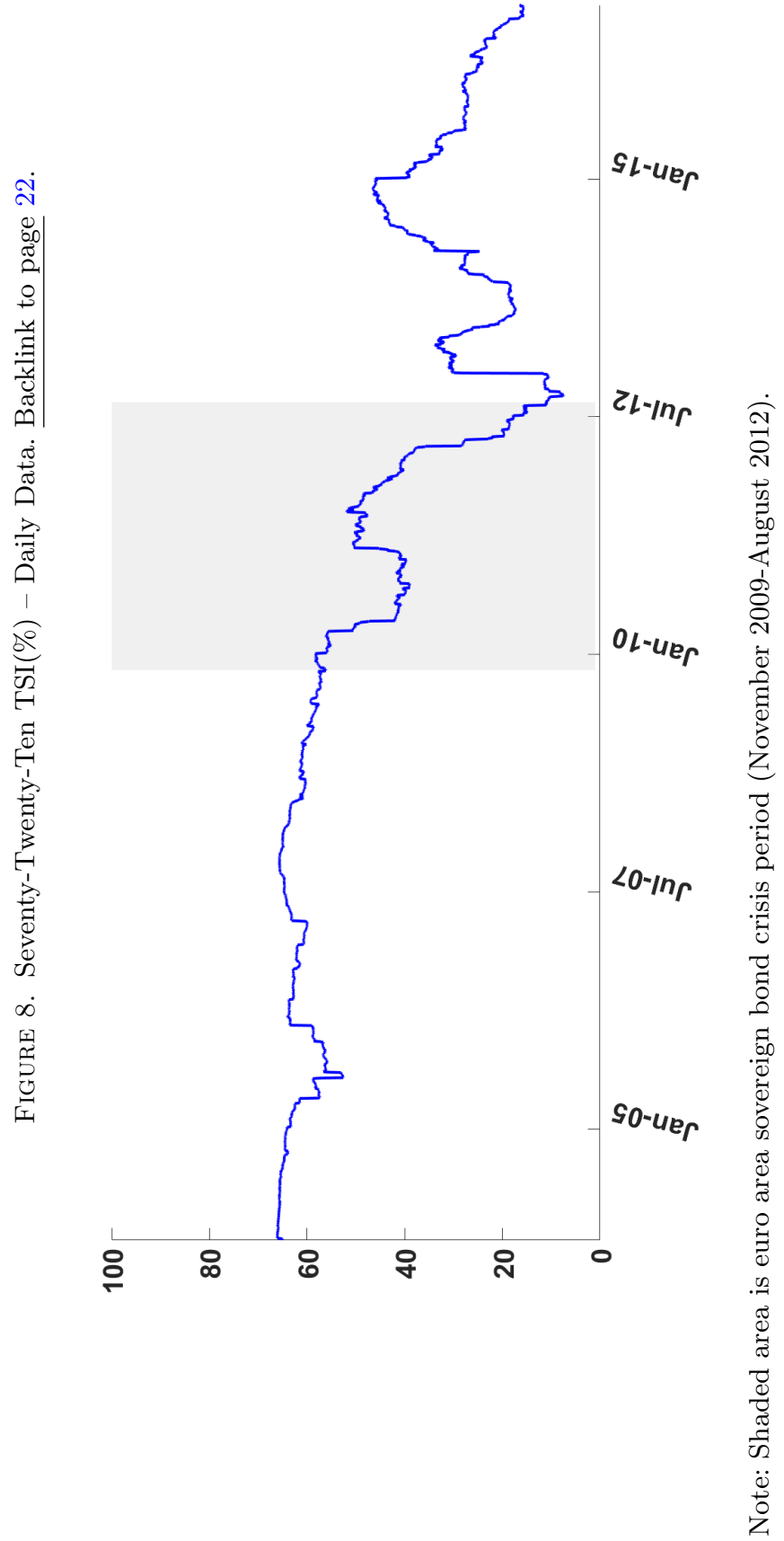




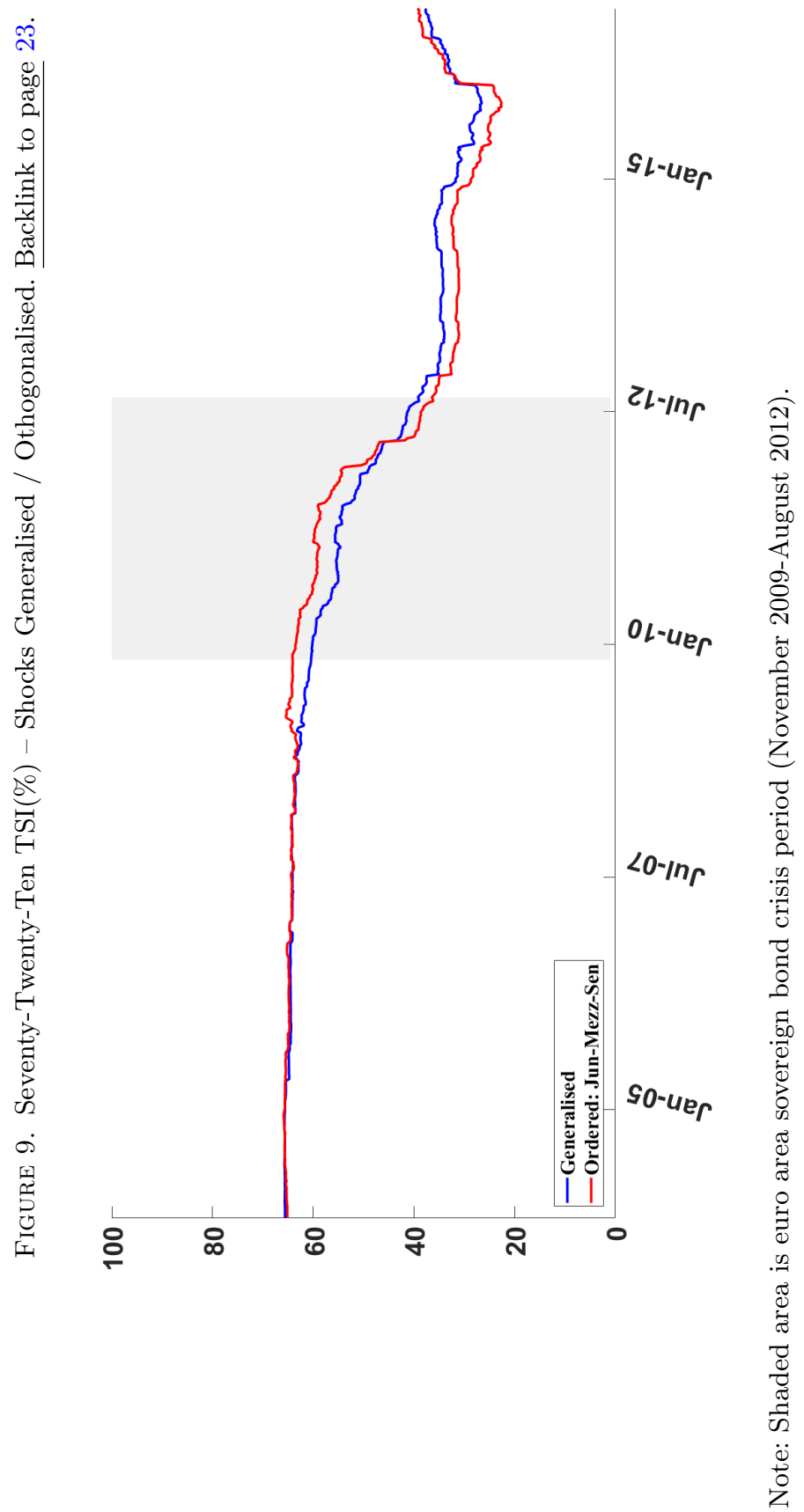




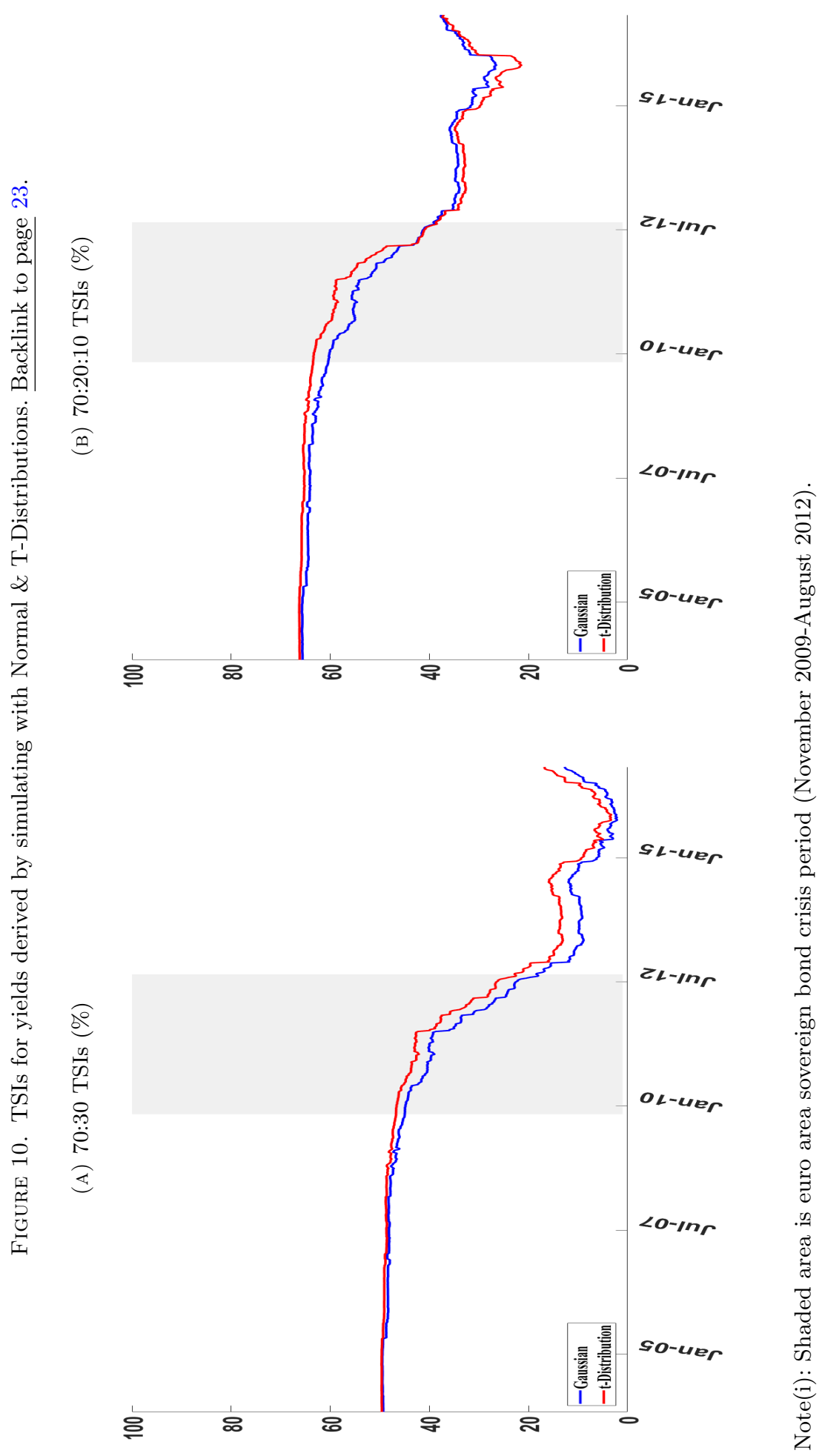




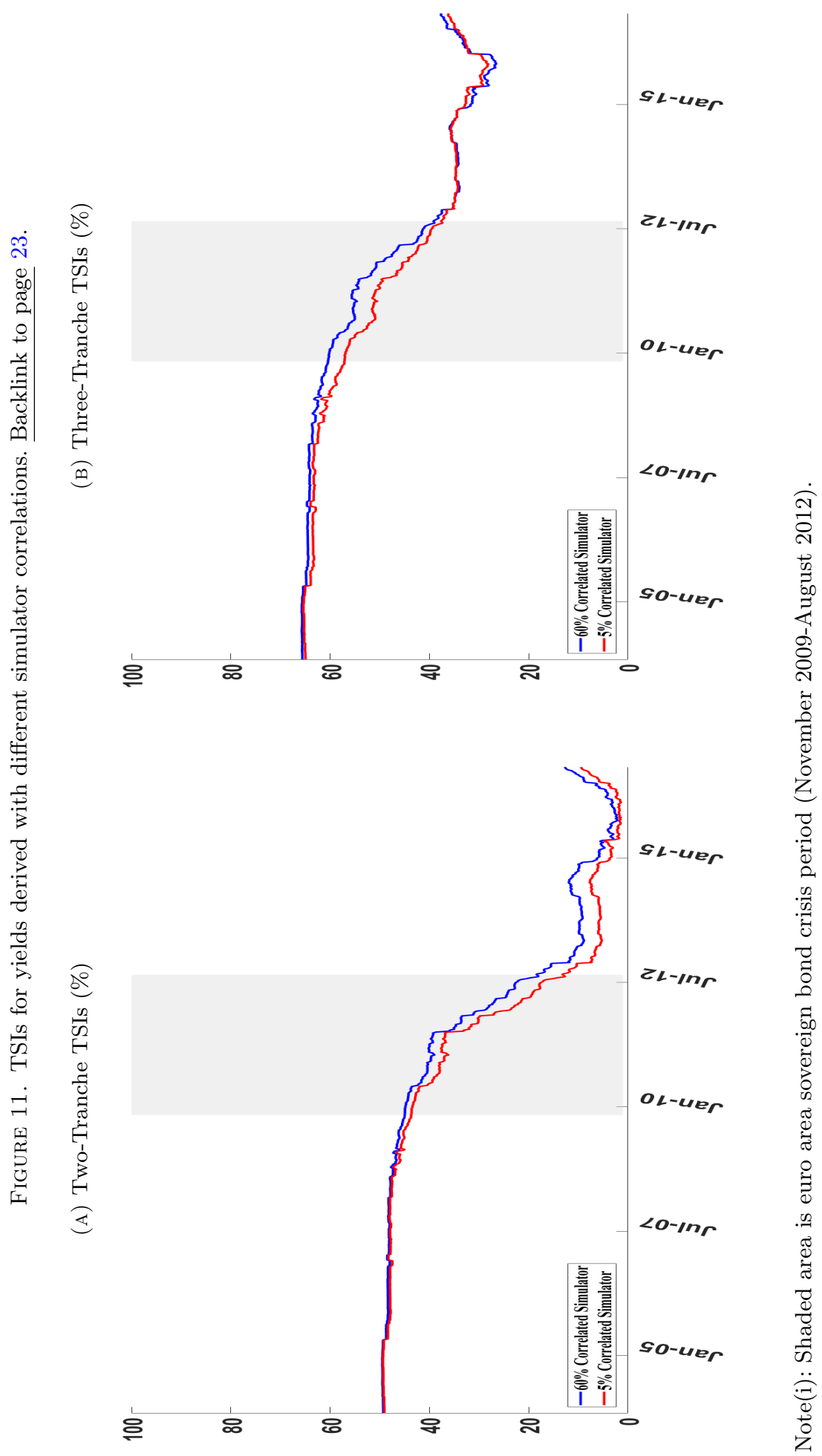

